\title{
Habgierige Götter, habgierige Städte Heiligtumsbesitz und Gebietsanspruch in den kretischen Staatsverträgen (1)
}

\section{EINLEITUNG}

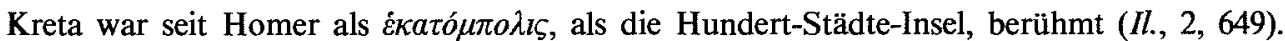
Es überrascht also niemanden, wenn die Existenz vieler unabhängiger Stadtstaaten auf einem sehr beschränkten Raum zu stetigen Rivalitäten, Konflikten und Kriegen führte $\left(^{2}\right)$. Bei den häufigen kretischen Kriegen ging es nicht so sehr um Macht oder um Hegemonie, sondern hauptsächlich um Land, um Lebensraum, in dem die meist kleinen Gemeinden ihre wirtschaftlichen Aktivitäten entfalten konnten. Gebietsansprüche und Grenzfragen bilden daher besonders häufig den Gegenstand der kretischen Staatsverträge $\left(^{3}\right)$.

Daß das Land von Heiligtümern sowie die Frage, welche Stadt ein Heiligtum besitzt, bei den kretischen Grenzziehungen eine gewichtige Rolle spielten, überrascht niemanden : Denn

(1) Für sprachliche Korrekturen danke ich Dr. J.-U. Krause. Alle chronologischen Angaben sind v. Chr. Zeitschriften werden nach der Année Philologique, epigraphische Publikationen nach dem $S E G$ abgekürzt. Für häufig zitierte Arbeiten werden folgende Abkürzungen verwendet :

Daverio Rocchi, Frontiera

FAure, Cavernes

HEGYI, Temene

KAHRSTEDT, Heiliges Land

VAN EFfenterre, Crète

VAN EFfenterre, Querelles

Van Effenterre-Bougrat, Lato
$=$ G. Daverio Rocchi, Frontiera e confini nella Grecia antica, Roma, 1988.

$=$ P. FAure, Fonctions des cavernes crétoises, Paris, 1964.

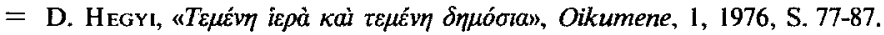

= U. Kahrstedt, "Delphoi und das Heilige Land des Apollon", in : G. E. Mylonas-D. Raymond (Hrsg.), Studies Presented to D. M. Robinson, St. Louis, 1953, S. 749-757.

$=\mathrm{H}$. Van Effenterre, La Crète et le monde grec de Platon à Polybe, Paris, 1948.

$=$ H. VAN EFFENTERRE, "Querelles crétoises», Revue des Études Anciennes $(=R E A), 44,1942$, S. 31-51.

$=$ H. VAN EFFENTERRE-M. Bougrat, «Les frontières de Lato", Kretika Chronika, 21, 1969, S. 9-53.

(2) Zu den kretischen Kriegen s. E. KIRsTEN, Das dorische Kreta I. Die Insel Kreta im 5. und 4. Jh., Würzburg, 1942, S. 30-32, 53-57, VAn Effenterre, Crète, bes. S. 28-30, 153-160, 185-191, 210-213, 253-254, 281, 288; R. F. WILlerts, Aristocratic Society in Ancient Crete, London, 1955, S. 225-246, bes. 234-246; A. PETropoulou, Beiträge zur Wirtschafts- und Gesellschaftsgeschichte Kretas in hellenistischer Zeit, Frankfurt, 1985, S. 15-27.

(3) I. Cret. I, viii, 4 = Staatsverträge II, 148 (Knosos-Tylisos, Mitte des 5. Jh.); I. Cret. I, xvi, 5 ; VAN EFFENTERRE, Querelles, S. 35-36; VAn Effenterre-Bougrat, Lato, S. $28-29$ (Lato-Olus, 121/20-111/10) ; l. Cret. III, iv, 9-10 (Itanos-Hierapytna, 114/3) ; I. Cret. III, iv, 9 Z. 57-60 (Dragmos-Itanos, frühes 2. Jh. ?) ; ebenda Z. $62-65$ (ItanosPraisos, frühes 2. Jh. ?); ebenda Z. 66-67 (Hierapytna-Praisos, frühes 2. Jh. ?) ; I. Cret. IV, 174 (Praisos-Gortyn, frühes 2. Jh.) ; I. Cret. IV, 182 (Teilung eines Territoriums zwischen Gortyn und Knosos, um 166/5);SEG XXVI, 1049; I. Cret. 1, xvi, 18 (Hierapytna-Lato-Lyttos-Olus, 111/10). H. VAN EFFENTERRE bietet einen Überblick über die kretischen Grenzziehungen in seinem Beitrag zum 4. Stuttgarter Kolloquium zur Historischen Geographie des Altertums («Die Grenze»), Stuttgart, 1990 (im Druck). 
einerseits lagen viele bedeutende Heiligtümer in der Eschatia kretischer Poleis, andererseits besaßen sie oft viel Land. Die Lage vieler kretischer Heiligtümer außerhalb der städtischen Zentren, in der Regel auf Bergen, erklärt sich aus der Geschichte der kretischen Religion und dem Charakter vieler kretischer Kulte, d.h. aus der besonderen Rolle von Kulten der Fruchtbarkeit und des vegetativen Gedeihens sowie aus der minoischen Vergangenheit zahlreicher Kultplätze (4). Die Existenz vieler großer Heiligtümer an der Grenze zwischen zweien oder mehreren Poleis - das Phänomen kennt man übrigens auch aus dem griechischen Festland (5) - führte oft zu Spannungen ; die angrenzenden Städte unternahmen den Versuch, das Heiligtum und natürlich sein Land unter ihre Kontrolle zu bringen. In der Tat finden wir in den kretischen Grenzbeschreibungen häufig Hinweise auf Kultorte, Tempel oder Heiligtümer, in deren Nähe die Grenze zwischen zwei Staaten verlief ${ }^{(6)}$. In all diesen Fällen befinden wir uns in einer Berglandschaft ; dort lagen die traditionsreichen und angesehenen Heiligtümer. Und gerade diese Landschaft war für die Viehzucht aüßerst wichtig. Konflikte zwischen den transhumanten Hirten, die diese schwer zu bestimmende und noch schwieriger zu kontrollierende

(4) Einige Beispiele über die große Entfernung bedeutender kretischer Heiligtïmer von städtischen Zentren : die

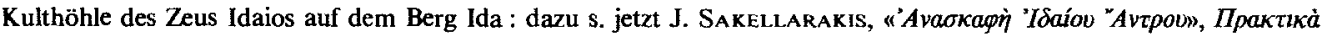

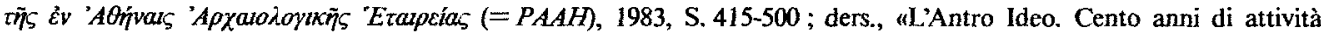
archeologicas, Atti dei Convegni Lincei, 74, 1985 (Cento anni di attività archeologica Italiana in Creta, Roma, 15 Gennaio 1985), S. 19.48; ders., "The Idean Cave : Minoan and Greek Worship", Kernos, 1, 1988, S. $207-214$ (mit der älteren Literatur); das Heiligtum des Poseidon auf dem Berg Juktas (lyktos) : s. I. Cret. I, viii, 4*, Z. 14-16; zur Geschichte des Kultplatzes s. jetzt A. Karetsou, "The Peak Sanctuary of Mt. Juktasn, in : R. Hägg-N. Marinatos (Eds.), Sanctuaries and Cults in the Aegean Bronze Age. Proceedings of the Ist Int. Symposium at the Swedish Institute in Athens, 12-13 May 1980, Stockholm, 1981, S. 137-153; das Heiligtum des Zeus Thenatas in Amnisos: s. jetzt J. Schafer (Hrsg.), Amnisos, Berlin, 1991 (mit der älteren Literatur); das Heiligtum des Hermes und der

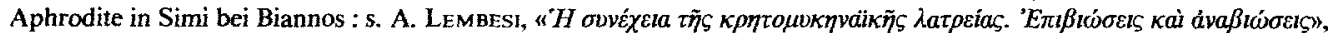

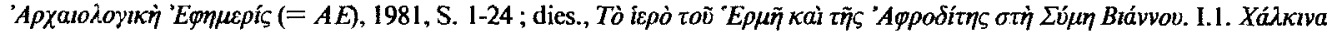

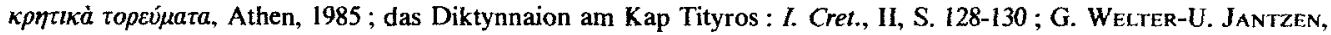
"Das Diktynnaion", in : F. MATz (Hrsg.), Funde auf Kreta, Berlin, 1951, S. 106-117; das Heiligtum der Athena Samonia am Kap Samonion: I. Cret., III, S. 156-158; das Heiligtum des Ares und der Aphrodite im Ort Sta Lenika zwischen Lato und Olus: J. Bousquer, «Le temple d'Aphrodite et d'Arès à Sta Lenikà», Bulletin de Correspondance Hellënique $(=B C H), 62,1938$, S. 386-408; die Kulthöhle der Eileithyia Inatie in Tsoutsouros (Inatos) : I. Cret., I,

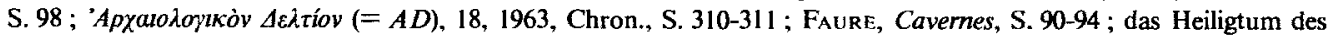
Pan (oder Hermes) Kypharissites : I. Cret. I, xvi, $7=S E G$, XXXIV, 920 ; das Heiligtum des Zeus Skylios : . Cret., I, xxix, 1 ; die Kulthöhle des Hermes Kranaios bei Patso : I. Cret., II, S. 102-103 ; Faure, Cavernes, 136-139; die Höhle von Arkoudia (Kydonia), gewidmet dem Kult des Apollon, der Artemis und der Nymphen: A. GuestPapamanoli-A. Lambraki, $A D, 31$ A, 1976, S. 237-242; SEG, XXXI, 816 ; die Kulthöhle des Pan und der Nymphen in Lera (Kydonia) : Guest-PAPamanoli-LambrakI, a.O., S. 179-237; SEG, XXXI, 815; das Heiligtum des Hermes Tallaios bei Melidoni : I. Cret., II, xxviii, I =SEG, XXXIII, 736 ; I. Cret., II, S. 302-304; Faure, Cavernes, S. $131-136$; das Heiligtum des Zeus Diktaios in Palaikastron: R. S. BosanqueT, "Dicte and the Temples of Dictaean Zeus", Annual of the British School at Athens, 40, 1939/40, S. 60-77; I. Cret., III, S. 5-9. Vgl. auch die Liste von Kulthöhlen in Faure, Cavernes, S. 190. Die minoische Vergangenheit des Kultes ist im Falle der Idäischen Grotte, des Kultortes auf dem Juktas, des Heiligtums in Simi und der Kulthöhlen von Inatos und Arkoudia gesichert, in Amnisos und Palaikastron wahrscheinlich.

(5) Beispiele : M. SARTRE, "Aspects économiques et aspects religieux de la frontière dans les cités grecques", Ktèma, 4, 1979, S. 222 ; F. DE Polignac, La naissance de la cité grecque, Paris, 1984, S. 46 ; Daverı Rocch, Frontiera, S. 5457.

(6) Einige Beispiele : I. Cret., I, xvi, 5 ; vgl. Van EfFenterre, Querelles, S. $35-36$ (Grenze von Lato und Olus): Kultorte des Hermes (Z. 55), der Kureten (Z. 60), des Zeus (Z. 62) und der Aphrodite (Z. 70) sowie ein Temenos (Z. 70) ; I. Cret., I, viii, $4^{*}=$ Staatsverträge, II, 148 (eine Gemarkung zwischen Knosos und Tylisos) : ein Heiligtum der Artemis (B7) sowie ein Temenos; I. Cret., IV, 174 (die Grenze von Priansos): Kultorte des Tantalos (Z. 20) und des Zcus Idatas (Z. 22-23). 
Grenze überquerten, lagen nahe ( 7 ). Die Frage, wer das Heiligtum und sein Land besitzt, war also von großem Gewicht, umsomehr als der Landbesitz der kretischen Heiligtümer oft beträchtlichen Umfang hatte $\left(^{8}\right)$.

\section{Streitigkeiten um Heiligtumer in Ostkreta}

Im folgenden werde ich von drei ausgewählten Beispielen ausgehen. Alle drei betreffen dasselbe Gebiet, Ostkreta, stammen aus derselben Zeit, ca. 121-110 v. Chr., und betreffen analoge Probleme, nämlich Gebietsansprüche. In allen drei Fällen spielt ein bedeutendes Heiligtum eine Rolle bei den Auseinandersetzungen um den Besitz des umstrittenen Landes; und dennoch lassen sich die drei Fälle nicht auf einen gemeinsamen Nenner bringen.

\section{Beispiel: Die Ansprüche von Lato und Olus auf das Heiligtum des Ares und der Aphrodite} in Sta Lenika (Dera) (Testimonien 1-3).

Im Jahr 121 brach ein Krieg zwischen Gortyn und Knosos aus, der sich schnell auf Ostkreta ausdehnte $\left({ }^{9}\right)$ : Lato, ein Verbündeter der Knosier, kämpfte gegen Olus, einen Verbündeten der Gortynier. Bei diesem Krieg ging es um den Besitz der Insel Pyrrha, um die Beute aus einem Schiffswrack und schließlich um den Besitz eines Heiligtums und seines Landes (Test. 2, Z. 44-49). Im Jahr 118 vermittelte Knosos zwischen Olus und Lato, und 115 kam es zu einem für die Latier günstigen Urteil (Test. 2), welches 113 von vier römischen Legati bestätigt wurde (Test. 3). Eine Kommission von Horothetai aus Milet setzte im Jahr 111/110 Grenzsteine ( ${ }^{(0)}$. Aus den einschlägigen Zeugnissen ergibt sich folgendes Bild :

1. Nicht weit vom heutigen Ort Sta Lenika existierte schon seit alten Zeiten ein Heiligtum

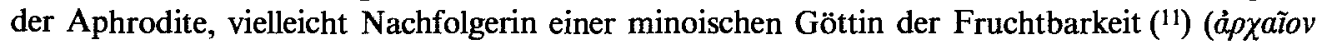
'Appodíaıov, Test. 2, Z. 52-53). In seiner Nähe, im Ort Dera, gab es auch ein Heiligtum des

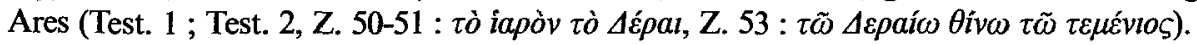

2. Das Heiligtum in Dera besaß ausgedehnte Ländereien. Diese Ländereien sind die $\Delta \varepsilon \rho a i ́ a$

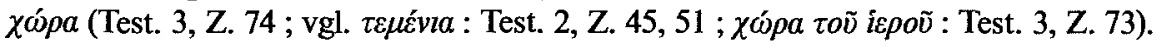

3. Im ausgehenden 2. Jh. wechselte das Heiligtum und sein Land oft den Besitzer; bald besaßen es die Latier, bald die Oluntier. Für einen kurzen Zeitraum gelangte es aber unter die Kontrolle

(7) Probleme der Transhumanz in kretischen Staatsverträgen : z.B. I. Cret., III, iv, $1=$ Staatsverträge, III, 554, Z. 33-68 (Vertrag zwischen Hierapytna und Praisos, fruhes 3. Jh.) ; das Weiden wird interessanterweise in zwei Temene verboten) ; vgl. I. Cret., III, iii, 4, Z. 27-30 (Vertrag zwischen Hierapytna und Priansos, frühes 2. Jh.). Mit Transhumanz hängt vielleicht auch eine frühe lyttische Inschrift (SEG, XXXV, 991 B) zusammen : vgl. H. VAN EFFENTERRE-M. VAN EFFEnTERRE, "Nouvelles lois archaiques de Lyttos", BCH, 109, 1985, S. 182-183.

(8) Allgemein zum Vermögen kretischer Heiligtümer s. Perropoulou, a. O. (Anm. 2), S. 85-86. Abgesehen von den unten behandelten Fälen gibt es Nachrichten (in der Hauptsache aus der Kaiserzeit) über den Landbesitz folgender Heiligtümer : Heiligtum des Asklepios in Knosos : I. Cret., I, viii, 49 ; A. Chavıoris, «Kleine Beiträge zu den kretischen Inschriften), Zeitschrift für Papyrologie und Epigraphik (=ZPE), 62, 1986, S. 193-194 (zu I. Cret., I, viii, 55); Heiligtum des Zeus Skylios in Rhytion : I. Cret., I, xxix, 1; Diktynnaion : I. Cret., II, xi, 3 (vgl. 6; I. Cret., IV, 334 ; SEG, XXIII, 531).

(9) Ober diese Ereignisse s. Van EfFenterre, Querelles, S. 31 -51 ; Van EfFenterre-Bougrat, Lato, S. 27-30; M. W. Baldwin Bowsky, «Portrait of a Polis : Lato pros Kamara (Crete) in the Late 2d c. B.C.H, Hesperia, 58, 1989, S. 338-342.

(10) Van Effenterre-Bougrat, Lato, S. 28-29.

(11) Van Effenterre, Querelles, S. 33. 
der Schiedsrichter, der Knosier. Denn im Abkommen über den Schiedsspruch der Knosier heißt es (Test. 1) :

"Das Abkommen soll aufgezeichnet werden in Knosos im Heiligtum des Apollon Delphinios und im Heiligtum des Ares in Dera, in Lato aber im Heiligtum der Eileithyia usw.».

Dera wurde also damals als Teil des knosischen Gebietes betrachtet. Ein knosischer Priester verwaltete das Heiligtum (Test. 3, Z. 66) ; denn das Urteil der Römer ist nicht nur an die zwei Parteien (Latier und Oluntier) gerichtet, sondern auch an einen Priester. Offensichtlich hatten die beiden Parteien das umstrittene Gebiet ihrem Schiedsrichter, Knosos, übergeben ( ${ }^{12}$ ).

4. Aus den Abkommen über den Schiedspruch der Knosier und dem Urteil der Knosier ergibt sich folgendes für die rechtliche Stellung des Heiligtums und seines Landes : Das Heiligtum bildete keine selbständige Größe ; es war ein Besitz, und zwar der Latier (Test. 2, Z. 49-51 :

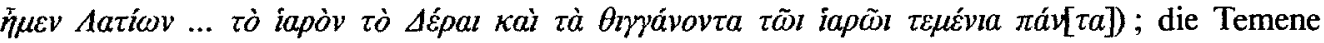
des Heiligtums werden als Teil des latischen Hoheitsgebietes aufgefaßt.

5. Die Fragen, wer das Heiligtum besaß und wer die Temene um das Heiligtum herum besaß, waren untrennbar miteinander verknüpft. Heiligtum und Land gehörten zusammen ; sie wechselten gleichzeitig den Besitzer. So entschieden die römischen Legati, als sie die Fürsorge für das Heiligtum derjenigen Stadt überließen, an deren Grenze das Heiligtum lag (Test. 3, Z. 7273) ; so hatten sich auch die Latier und die Oluntier entschieden, als sie Heiligtum und Land an ihren Schiedsrichter übergaben.

6. Die Auffassung der römischen Legati scheint sich aber von der Auffassung der knosischen Richter zu unterscheiden. Für sie ist das Heiligtum eine selbständige Größe. Das römische Urteil spricht nicht vom Besitz des Heiligtums und seines Landes, sondern von Fürsorge,

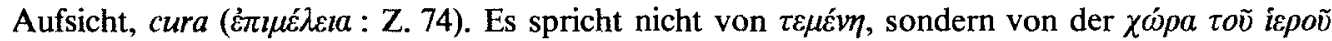
(Z. 73), vom Land des Heiligtums, und verwendet dabei den terminus technicus für Hoheits-

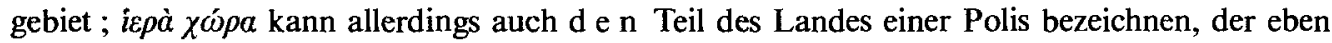

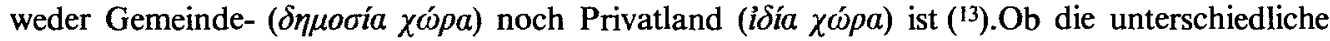
Auffassung der Römer auch einem älteren Status des Heiligtums entsprach, wissen wir nicht. Auf jeden Fall geht aus einem zeitgenössischen Urteil magnetischer Richter in einer analogen Auseinandersetzung zwischen Hierapytna und Itanos (3. Beispiel) hervor, daß die Römer den

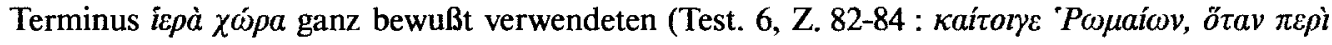

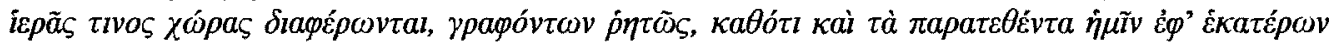

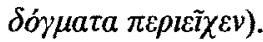

7. Die Fürsorge für das Heiligtum ( $\dot{\pi} \iota \mu \dot{\varepsilon} \lambda \varepsilon ı a)$ - d.h. unter anderem welche Stadt den Priester stellt, der Gottheit opfert, die Bauarbeiten durchführt - ist vom Besitz des Landes untrennbar, sie hängt mit rechtlichen Ansprüchen zusammen. Solange das Heiligtum in Dera von einem knosischen Priester verwaltet wurde, wurde Dera als Teil des knosischen Hoheitsgebietes betrachtet (s.o.); sowie es die Latier erhielten, führten ihre Beamten die Bauarbeiten durch und brachten die Weihungen dar $\left({ }^{14}\right)$.

Wir belassen es vorläufig bei diesen sieben Punkten und wenden uns einem zweiten Beispiel zu :

(12) Vgl. VAN EFFEnTERre, Querelles, S. 42.

(13) HeGYi, Temene, S. 77-78.

(14) Uber diese Bauarbeiten s. I. Cret., I, xiv, 2; xvi, 24-34; Bousouet, a.o. (Anm. 4), S. 390 Nr. 1, S. 404405 Nr. $3-4$; VAN EFfFierre-Bougrat, Lato, S. 28 ff. 


\section{Beispiel : Die Grenze zwischen Lato und Hierapytna (Testimonium 4)}

Nach der Beendigung dieser Kriege in Ostkreta schlossen Lato und Hierapytna einen Bündnisvertrag (111/110 v. Chr.); die zwei Städte gehörten früher zwei verschiedenen Bündnissen an : Lato war mit Knosos, Hierapytna mit Gortyn verbündet. Im Bündnis- und Isopolitievertrag wird auch ihre gemeinsame Grenze festgesetzt. In diesem Grenzvertrag (Test. 4) ist in Z. 62

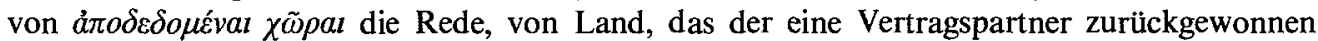
hatte (dabei geht es um das zwischen Lato und Olus strittige Land) ( ${ }^{15}$ ). Nachdem die Grenze dieses Landes beschrieben wird, wird ein weiteres Land beschrieben (Test. 4, Z. 69 ff.) ; trotz des fragmentarischen Zustandes dieser Stelle, kann man davon ausgehen, daß die Hierapytnier

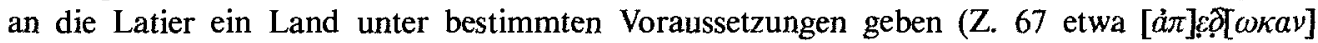
$\delta \dot{\varepsilon} \kappa \lambda \pi$.) (16) :

"Auch die Hierapytnier haben den Latiern Land [zurückgegeben bzw. übergeben], wie die Latier aufforderten, unter der Voraussetzung, daß die Latier dem Bündnis der Lyttier (?) ( $\left.{ }^{17}\right)$ und der Hierapytnier treu bleiben ; die Grenzen dieses Landes sind die folgenden» (Z. 67-69).

Der Beschreibung der Grenze schließt sich dann folgender Eintrag an (Z. 81) : غ̇ंì $\delta \dot{\varepsilon} \tau \tilde{\omega}$

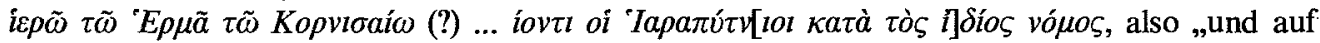
dem Heiligtum des Hermes Kornisaios (?) [ein Verb] die Hierapytnier gemäß ihren eigenen Gesetzen“. Nur die Ergänzung $[\theta v \sigma] i ́ o v \tau l=\theta v \sigma \sigma o v \sigma l\left({ }^{18}\right)$, "werden opfern" macht m.E. einen Sinn. Die Hierapytnier behalten das Recht, in diesem Hermesheiligtum nach ihren eigenen Gesetzen zu opfern, und zwar nicht als Privatpersonen, sondern als Gemeinde, als Staat. Diese Bestimmung muß mit der Rück-bzw. Übergabe des Landes zusammenhängen; wahrscheinlich lag dieser Kultort unmittelbar an der Grenze, es ist wohl eins der Orientierungspunkte dieser

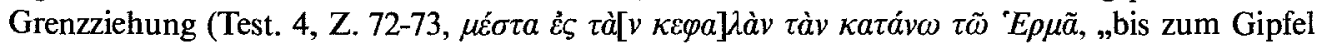
oberhalb des Hermes“) ${ }^{\left({ }^{19}\right)}$. Das Heiligtum des Hermes lag sicher $n \mathrm{icht}$ im Territorium von Hierapytna, denn dann bräuchte man den Hierapytniern das Opferrecht nicht zu gewähren ; das würde sich von selbst verstehen. Denn der Besitzer eines Landes hat das Recht, nicht nur das Land zu nutzen, sondern auch an den dort liegenden Heiligtümern zu opfern : [ع̌ $\chi \varepsilon r v]$,

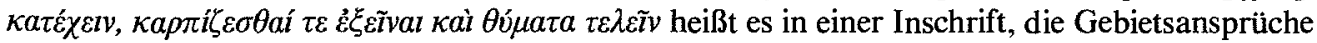
von Itanos und Hierapytna (s.u.) betrifft $\left({ }^{20}\right)$. Wenn aber in diesem Vertrag das Opferrecht Gegenstand gesonderter Regelung bildet, kann es nur zwei Deutungsmöglichkeiten geben :

1. Das Heiligtum lag im Territorium von Lato und zwar im von den Hierapytniern zurückgegebenem bzw. übergebenem Land; der Vertrag sicherte den Hierapytniern weiterhin die Ausübung eines alten Kultes; ob aber auch die Latier parallel zu den Hierapytniern am Kult

(15) Van Effenterre-Bougrat, Lato, S. 19.

(16) Vgl. Van EFFenterre-Bougrat, Lato, S. 19 : «un verbe exprimant une concession des Hiérapytniens aux

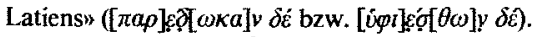

(17) Y. Garlan, «Études d'histoire militaire et diplomatique», $B C H, 100,1976$, S. 304, liest an dieser Stelle, statt

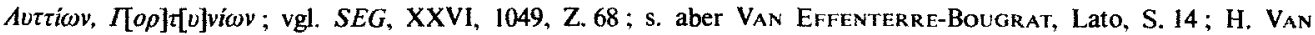
EFFenterRe, «Préliminaires épigraphiques aux études d'histoire du droit grec», in: F. Javier-F. Nifto (Hrsg.), Symposion 1982. Vorträge zur griechischen und hellenistischen Rechtsgeschichte (Santander, 1.-4. September 1982),

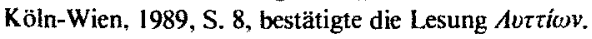

(18) Vgl. Van Effenterre-Bovgrat, Lato, S. 23 : won attend un verbe de prescription au futur indiquant le droit reconnu aux Hiérapytniens sur le sanctuaire ou auprès de lui".

(19) Zur besonderen Beziehung des Hermes 7u Grenzen : SARTrE, a.O. (Anm, 5), S. 221-222.

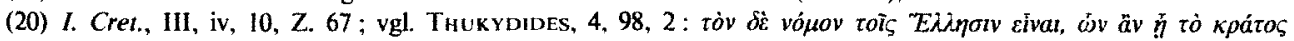

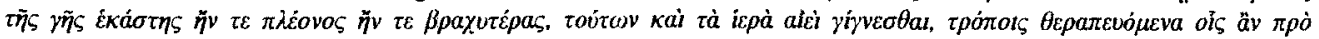

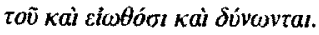


teilnahmen, steht nicht fest. Die Formulierung vermittelt auf jeden Fall den Eindruck, daß die Hierapytnier und sie allein für das Opfer zuständig waren.

2. Das Heiligtum des Hermes besaß eine Sonderstellung. Es gab keinen Besitzer des Heiligtums und seines Landes; sein Land war Niemandsland. Der Vertrag bestimmte nur, welche Stadt für das Opfern zuständig sein sollte.

Für die erste Deutung fehlen die Parallelen ( $\left.{ }^{21}\right)$. Für die zweite Erklärung gibt es dagegen eine gute kretische Parallele : Ein sehr früher Staatsvertrag zwischen Knosos und Tylisos, aus der Mitte der 5. Jh., enthält neben vielen Bestimmungen über gemeinsame Opfer, Feste und Weihungen auch eine Bestimmung darüber, wer für das Opfer an Poseidon auf dem Berg Iytos (heute Juktas), an der Grenze zwischen den beiden Städten, zuständig sein sollte (Test. 5). Diese Aufgabe wurde dem knosischen Priester überlassen (Test. 5, A 14-16). Eine analoge Bestimmung betraf das Opfer an Ares und Aphrodite in einem nicht näher zu lokalisierenden Kultort (Test. 5, B 14-15). Wenn wir eine derartige Bestimmung im Vertrag zwischen Knosos und Tylisos finden, muß die Zugehörigkeit dieser Kultorte zum Territorium von Knosos bzw. Tylisos nicht eindeutig gewesen sein; sie waren eben Niemandsland. Ähnlich haben wir uns wohl auch die Stellung des Hermesheiligtums vorzustellen.

Festzuhalten ist auf jeden Fall, daß sich dieses Abkommen zwischen Lato und Hierapytna vom Streit zwischen Lato und Olus deutlich unterscheidet. Im ersten Fall gingen Heiligtumsbesitz

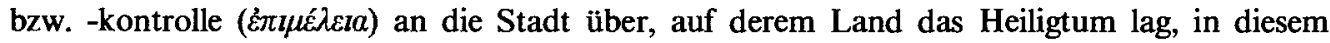
Fall gewiß nicht, auch wenn die genaue rechtliche Stellung des Hermesheiligtums nicht ganz sicher ist.

\section{Beispiel: Der Streit zwischen Itanos und Hierapytna um das Land in der Nähe des Heiligtums} des Zeus Diktaios (Test. 6-7).

Zwischen Itanos und Praisos lag das Heiligtum des Zeus Diktaios am heutigen Ort Palaikastron (22). Itanos' Territorium grenzte an das Land des Heiligtums an (Test. 6, Z. 38). Hierapytna besiegte um 145 v. Chr. die Stadt Praisos, zerstörte sie und verleibte sich ihr Territorium ein (Test. 6, Z. 68-69). Prompt fingen Itanier und Hierapytnier an, über die gemeinsame Grenze und vor allem über das Land in der Nähe des Heiligtums zu streiten (Z. 47). Eine römische Gesandtschaft unter Servius Sulpicius Galba setzte 141 v. Chr. dem Krieg ein Ende (Z. 53), und ein Gericht in Magnesia gab das umstrittene Land den Itaniern. Es folgte ein neuer Krieg zwischen Hierapytna und Itanos, die Hierapytnier besetzten das

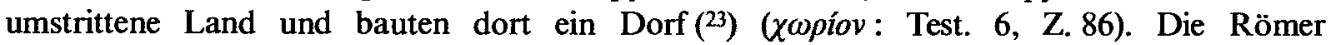
intervenierten erneut (114 v. Chr.) und ein Gericht in Magnesia bestätigte 113/112 das alte Urteil ${ }^{(24)}$. Für unsere Fragestellung über die rechtliche Stellung des Heiligtums und seines Landes sind die Argumente der beiden Parteien von Belang. Ich versuche diese Argumentation aufgrund des Urteils der Magneten zu rekonstruieren :

(21) Die Kultorte, die Körperschaften von Fremden auf dem Gebiet einer Polis mit besonderer Genehmigung gründen - z.B. die von ägyptischen bzw. zypriotischen Händlern errichteten Heiligtümer für Isis bzw. Aphrodite in Athen $\left(I G, \mathrm{II}^{2}, 337\right)$ - sind hiermit nicht vergleichbar.

(22) Zum Heiligtum s. Anm. 4.

(23) M. BiLE, "Le vocabulaire du village dans les inscriptions crétoises", Ktèma, 11, 1986, S. 141 ; vgl. VAN Effenterre, Crète, S. 304, Anm. 1.

(24) $\mathrm{Zu}$ den historischen Ereignissen: J. PARTsCH, Die Schriftformel im römischen Provinzialprozesse, Breslau, 1905, 5 ff. ; M. Cary, "A Roman Arbitration of the Second Century B.C.", Journal of Roman Studies, 16, 1926, S. 194-200; Bosanquet, a.O. (Anm. 4), S. 73-75 ; VAn EFFenterre, Querelles, S. 43-44; I. Cret., III, S. $91-92$; R. K. ShERK, Roman Documents from the Greek East, Baltimore, 1969, S. 78-85, Nr. 14. 
1. Die Auffassung der Hierapytnier :

Das Land gehörte nicht den Itaniern, sondern dem Zeus Diktaios; es war heiliges Land,

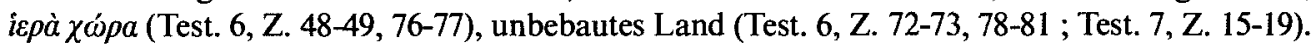
Um den Römern zu erklären, warum sie selbst dort ein $\chi \omega$ piov gebaut hatten, haben sie wahrscheinlich behauptet, daß dieses Land ursprünglich ihnen gehört hatte (Test. 7, Z. 14 :

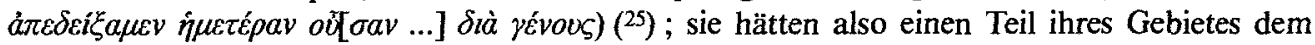
Zeus Diktaios als ípà $\chi \omega ́ \rho a$ geweiht.

\section{Die Auffassung der Itanier :}

Die Auffassung der Itanier ist eine grundsätzlich andere. Das umstrittene Land gehört ihnen

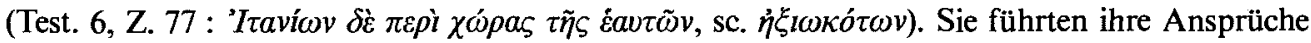

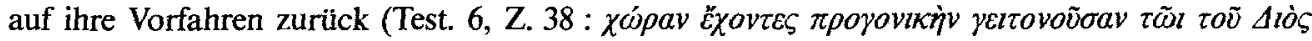

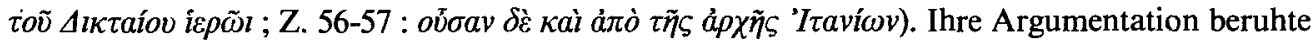
auf einer völligen Trennung zwischen Heiligtum des Zeus Diktaios einerseits und umstrittenem

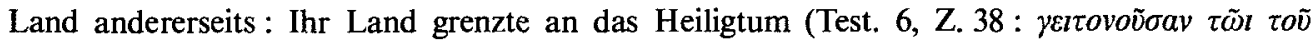

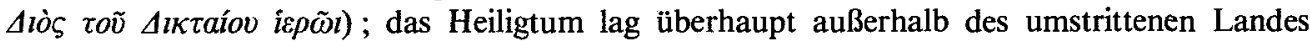

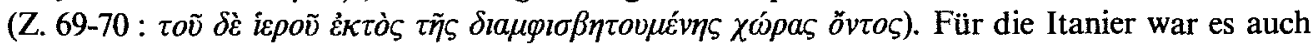
belanglos, wer das Heiligtum momentan kontrollierte. Gegen das Argument der Hierapytnier, $\mathrm{da} ß$ das Land dem Zeus Diktaios gehörte, wiesen sie die Richter auf die Tatsache hin, daß

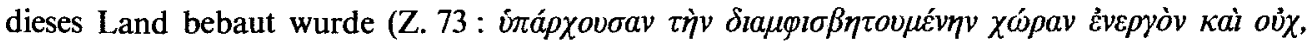
ஸ́s Ě konstatiert : In ihrem Brief ist nicht von "heiligem Land" die Rede, sondern von "landwirtschaftlicher Nutzung" ( $\kappa a \rho \pi i \zeta \varepsilon \sigma \theta a l$ ) des Landes (Test. 6, Z. 76-81) ; ja selbst die Hierapytnier hatten das Land landwirtschaftlich genutzt, indem sie dort ein $\chi \omega \rho$ íov bauten (Z. 86).

Die Richter folgten in ihrem Urteil der Auffassung der Itanier. Statt der Frage nachzugehen, ob das Land den Hierapytniern oder den Itaniern gehörte, stellten die Richter nur die Frage, ob das Land bebaut wurde, mit anderen Worten, ob es dem Zeus Diktaios heilig war. Durch diese Definition der Problematik entzogen die Richter den Hierapytniern jede Gewinnchance; denn, wenn das Land heilig war, dann gehörte es dem Gott; die Hierapytnier hatten kein Recht, es zu bebauen und ihr Dorf dort zu gründen; wenn nicht, dann gehörte es den Itaniern.

Wichtig ist in unserem Zusammenhang die Tatsache, daß weder die Itanier noch die Hierapytnier auf die Frage eingingen, wem das Heiligtum selbst gehörte. Die Ausdruckweise vermittelt vielmehr den Eindruck, daß vor allem die Itanier das Heiligtum als eine selbständige Größe betrachteten : Nach ihrer Auffassung grenzte ihr Land nicht an das Hoheitsgebiet einer anderen

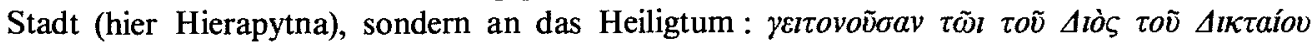

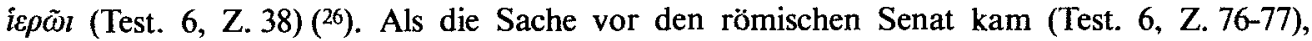
beanspruchten die Itanier das Land für sich ( $\pi \varepsilon \rho \grave{l} \chi \dot{\omega} \rho a \varsigma \tau \tilde{\eta} \varsigma \dot{\varepsilon} a v \tau \tilde{\omega} v)$, die Hierapytnier dagegen

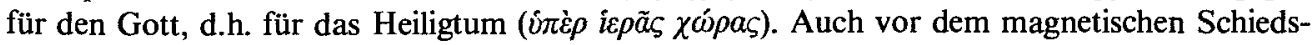
gericht unterschieden die Hierapytnier zwischen ihrem eigenen Besitz ( $\dot{\varepsilon} a v \tau \tilde{\omega} v)$ und dem Heilig-

(25) Hier ist sicher von dieser $\chi \omega ́ p a$ die Rede, und nicht von einem anderen strittigen Punkt, der Insel Leuke, die erst in Test. 7, Z. 16 erwähnt wird.

(26) Vgl. die Trennung der heiligen Domäne (icpà $\chi \hat{\omega} p a$ ) des Apollon Pythios vom Territorium der umliegenden Stadtstaaten (u.a. auch vom Territorium von Delphi); die angrenzenden Poleis werden in einer Inschrift genannt, die die Grenze dieser Domäne beschreibt (117 v. Chr.): Syll. ${ }^{3}, 826$ E. Zur richtigen Deutung des Textes s. KAHRSTEDT, Heiliges Land, S. 752-754. 


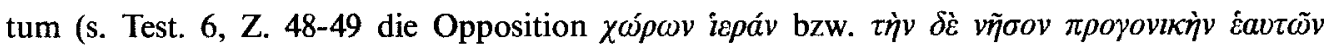

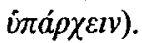

Leider wurde der Ausdruck i $\varepsilon \rho \grave{a} \chi \chi \dot{\omega} \rho a$ im Altertum nicht einheitlich verwendet; er kann sowohl das Land von Heiligtümern bezeichnen, das zum Territorium keiner Polis gehört (27) als auch das Land von Heiligtümern auf dem Hoheitsgebiet einer Polis, also das "heilige Land" im Unterschied zum Gemeinde- und zum Privatland (28).

Es gibt jedoch einige Hinweise, daß das Heiligtum des Zeus Diktaios ursprünglich den Status eines nicht einer einzigen Stadt gehörigen Heiligtums hatte, das erst im Lauf des 2. Jh. unter die Kontrolle der Hierapytnier gelangte $\left.{ }^{(29}\right)$. Im berühmten Kuretenhymnus, dem Hymnus für den dort verehrten Zeus ${ }^{30}$ ), wird der Gott gebeten, mehrere Städte zu beschützen ([0ópg $\left.\kappa \dot{\varepsilon} \zeta\right]$ $\pi \dot{x} \lambda \eta a_{S} \hat{\alpha} \mu \tilde{\omega} \nu$, Z. 29) ; der Hymnus wurde also möglicherweise von Epheben mehrerer Poleis gesungen ( ${ }^{31}$ ). Aus dem Heiligtum stammen ferner Dachziegel aus dem 3. Jh. v. Chr. mit dem

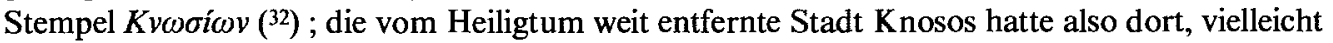
zusammen mit anderen Städten, Bauarbeiten durchgeführt, sicher nicht als Besitzer des Heiligtums. Der dort verehrte Gott, Zeus Diktaios, erscheint schließlich an vornehmer Stelle in Vertragseiden mindestens dreier Städte, Praisos (frühes 3. Jh.), Itanos (3. Jh.) und Hierapytna (2. Jh.) ( ${ }^{33}$ ). Obwohl wir also nicht mit Sicherheit sagen können, ob das Heiligtum das Zentrum einer Amphiktyonie war, scheint es auf jeden Fall nicht das Heiligtum einer einzigen Stadt gewesen zu sein. Wohl erst in der Zeit der Expansion Hierapytnas in diesem Gebiet (seit dem 2. Jh.) gelangte es unter ausschließlich hierapytnische Kontrolle ( $\left.{ }^{34}\right)$.

(27) So z.B. die ípà $\chi \omega ́ p a$ des Apollon Pythios in Delphi, des Apollon Ptoos und eines zwischen dem Phthiotischen Theben und Halos liegenden Heiligtums : s.u. Anm. 28.

(28) HegYi, Temene, s. 77-78 mit Anm. 6. Nur einige der dort zusammengestellten Texte belegen dies ( $S y l l .^{3} 633$ Z. 82 ; Syll. ${ }^{3} 679$; SCHWYzER, 488-490). Die anderen Belege haben mit diesem Sachverhalt nichts zu tun: In Syll. ${ }^{3}$ 826 E (vgl. Syll. ${ }^{3} 610$ Z. 1-2; IG $\mathrm{II}^{2}, 1126$; SEG XXVII, 123) ist die iepà $\chi \dot{\omega} \rho a$ des Apollon Pythios vom Land der Polis Delphi völlig zu trennen: s. Kahrstedt, Heiliges Land, S. 751 ; auch die ícà $\chi \omega ́ p a$ des Apollon Ptoos, die ein amphiktionisches Dekret ca. 228/226 für unverletzlich erklärte (Syll. $\left.{ }^{3} 635=L S S, 73\right)$, ist wahrscheinlich vom Territorium der Stadt Akraiphia zu trennen; in Syll. ${ }^{3}, 1009$, Z. 7-8 ist nicht von icpà $\chi \omega ́ p a \alpha$ die Rede, sondern von

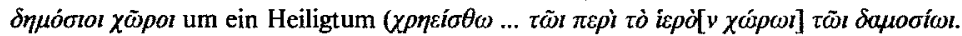

(29) Vgl. I. Cret., III, S. 6; H. Verbruggen, Le Zeus crétois, Paris, 1981, S. 109.

(30) $I$. Cret., III, ii, 2 ; dazu s. jetzt VerbrugGen, a.O., S. 101-111 mit der älteren Literatur; hinzuzufügen ist $S E G, \mathrm{XXVIII,} 751$.

(31) I. Cret., III, S. 17 ; Verbruggen, a.O., S. 109.

(32) I. Cret., III, ii, 3-4. Dachziegel, die Stempel mit dem Namen einer Gemeinde, oft auch mit der Bezeichnung

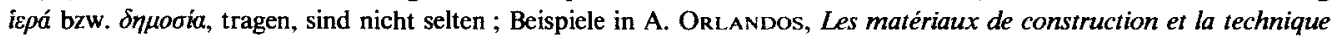
architecturale des anciens Grecs, I, Paris, 1966, S. 93-95; R. FELSCH, "Boiotische Ziegelwerkstätten archaischer Zeit», Mitteilungen des Deutschen Archöologischen Instituts (Athen) $(=M D A I(A)), 94,1979, \mathrm{~S} .21,31 \mathrm{Nr}$. E 3. Anders als die Personennamen, die nicht nur den Dedikanten, sondern oft auch den Hersteller nennen können, sind die Stempel mit Ethnika wohl als Stiftermarken zu deuten; sie bezeichnen den Auftraggeber : s. Orlanbos, a.O., S. 9395 ; G. HUbner, «Antefixa Deorum Athenarum», MDAI (A), 91, 1976, S. 180, Anm. 29; vgl. F. G. MAier, Griechische Mauerbauinschriften, II, Heidelberg, 1961, S. 50-51.

(33) I. Cret., III, iii, 5, Z. 11-12 (Isopolitievertrag zwischen Hierapytna und seinen Kolonisten, 2. Jh.); SEG, XXVI, 1049, Z. 83 (Bündnis- und Isopolitievertrag zwischen Hierapytna und Lato, 111/10); I. Cret., III, iv, 8, Z. 3 (Bürgereid von Itanos, 3. Jh.); ergänzt in I. Cret., III, vi, 7 = Staatsverträge, III, 553 A 15-16 (Vertrag zwischen Praisos und Stalis, frühes 3. Jh.). Die Anrufung des Gottes in den praisischen und hierapytnischen Eiden kann allerdings auch einfach damit zusammenhängen, daß das Heiligtum des Zeus Diktaios ursprünglich von Praisos, später aber von Hierapytna kontrolliert wurde; vgl. M. GuarducC, I. Cret., III, S. 6, 11, 17.

(34) So können die von hierapytnischen Beamten durchgeführten Statuenreparaturen um die Mitte des 2. Jh. (I. Cret., III, ii, 1) sowie die Aufstellung eines Vertrages zwischen Hierapytna und Knosos in diesem Heiligtum (I. Cret., I, viii, $13=$ III, S. 17) erklärt werden. 


\section{Heiligtumer im Dienst der aussenpolitischen Ziele kretischer Städte}

Fassen wir also zusammen : Vier ostkretische Städte, Lato, Olus, Hierapytna und Itanos waren im ausgehenden $2 . \mathrm{Jh}$. in einer Reihe von Kriegen und Auseinandersetzungen verwickelt. Immer ging es um Land, unter anderem auch um das Land eines Heiligtums oder um das Land um ein Heiligtum herum. Trotz großer Unterschiede im Detail war bei zwei besser bekannten Auseinandersetzungen (Lato-Olus, Hierapytna-Itanos) die rechtliche Stellung des Heiligtums bzw. seines Landes die Grundlage für die Entscheidung der Richter darüber, welcher Polis das strittige Land zuzusprechen war: Die knosischen Richter (1. Beispiel) hatten festzustellen, welcher Stadt das Heiligtum in Dera (Sta Lenika) gehörte ; diese Stadt würde dann auch Besitzer des Landes des Heiligtums werden (Test. 2). Die römischen Schiedsrichter formulierten die Frage etwas anders: Es galt festzustellen, an wessen Grenze das Heiligtum lag; diese Stadt würde dann Herr über Heiligtum und Heiligtumsland sein (Test. 3). Die magnetischen Schiedsrichter hatten schließlich zu beurteilen, ob das zwischen Itanos und

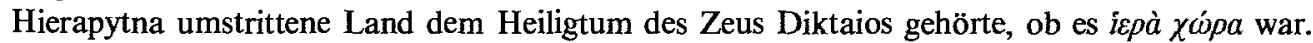

Obwohl es immer um Land von Heiligtümern ging, traten in keinem Fall irgendwelche Vertreter der Heiligtümer auf. Der Priester des Heiligtums in Dera erhielt zwar das Urteil der

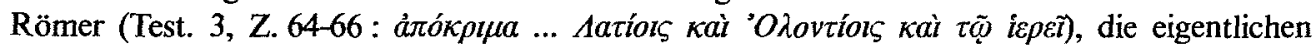
Prozeßparteien waren jedoch nur die Latier und die Oluntier (Test. 3, Z. 66-67 : Ĕאplvav Aatiols

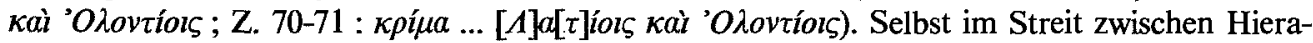
pytna und Itanos, in dem es eigentlich darum ging, ob die Itanier oder das Heiligtum ein bestimmtes Landstück besitzen sollten, wurden die Besitzrechte des Heiligtums von der Stadt Hierapytna verteidigt ; diese Stadt erkannte dem Heiligtum eine eigene ífó $\chi \dot{\omega} \rho a$ zu, faktisch aber kontrollierte sie es.

Alles in allem spielten die kretischen Heiligtümer zwar eine wichtige Rolle bei den behandelten Auseinandersetzungen, stets jedoch als untergeordnete Größen, abhängig von Städten und deren außenpolitischen Interessen - ein auch sonst in der griechischen Geschichte bekanntes Phänomen.

Im übrigen konnten die kretischen Heiligtümer auch auf andere Weise die außenpolitischen Ziele der Stadt unterstützen, die sie kontrollierte oder besaß : So z.B. manifestierten mächtige Städte ihre Vormachtstellung, indem sie mehr oder weniger abhängige Gemeinden bzw. Bundesgenossen zu finanziellen Leistungen an ein von ihnen kontrolliertes Heiligtum verpflichteten (35). Obwohl also die Bedeutung von Heiligtümern in den kretischen Staatsverträgen unbestreitbar ist, ist ebenso unbestreitbar, daß die profanen Instanzen und die außenpolitischen Ziele die maßgebende Rolle spielten.

Und dennoch gibt es in diesem Material Hinweise darauf, daß es nicht immer so war, daß manche kretische Heiligtümer früher eine gewisse Sonderstellung besaßen. Diesen Spuren einer älteren, differenzierteren Situation wollen wir jetzt in unserem späthellenistischen Material nachgehen.

(35) Ein Teil der gemeinsamen Beute der Knosier und der Tylisier wurde im knosischen Aresheiligtum geweiht: 1. Cret., I, viii, $4^{*}=$ Staatsverträge, II, 148 A $10-11$ (Vertrag zwischen Knosos und Tylisos, Mitte des 5. Sh.); die von Gortyn abhängigen Rhizenier wurden von Gortyn verpflichtet, das Opfer an Zeus Idaios zu finanzieren bzw. mitzufinanzieren : I. Cret., IV, 80 = Staatsverträge, II, 216, Z. 2-3 (Vertrag zwischen Gortyn und Rhizenia, spätes 5. Jh.); die von Gortyn abhängige Gemeinde der Bewohner der Insel Kaudos lieferte an das Pythion von Gortyn den Zehnten des Strandgutes : I. Cret., IV, 184 A 18-19 (frühes 2. Jh.). 


\section{Drei unterschiedliche rechtliche Stellungen Kretischer Heiligtumer?}

Aus der Argumentation der Gegner und den Urteilen der Gerichte geht hervor, daß sich die Heiligtümer unserer ausgewählten Beispiele in drei verschiedene Kategorien einordnen lassen, was ihre rechtliche Stellung betrifft :

1. Heiligtümer als Besitz derjenigen Stadt, auf deren Territorium sie liegen (Heiligtum des

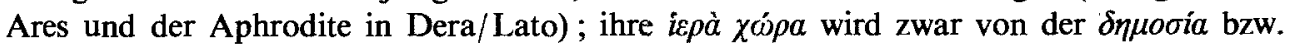

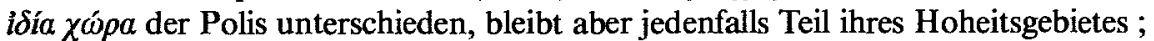

2. "überstädtische" Heiligtümer, wahrscheinlich Heiligtümer einer Amphiktionie, auf einer icpà $\chi \omega ́ \rho a$, die zum Land keiner Polis gehört (Heiligtum des Zeus Diktaios) ; und

3. Heiligtümer im Niemandsland, deren Fürsorge eine Nachbarstadt hat (Heiligtum des Hermes Kornisaios).

Dieses Ergebnis ist, das möchte ich betonen, angesichts der Lücken unseres Materials in manchen Punkten nicht ganz gesichert; es würde jedoch an sich niemanden überraschen, denn wir kennen auch sonst in Griechenland Heiligtümer verschiedener rechtlicher Stellungen. Unsere erste Kategorie stellt die Regel dar. Obwohl Heiligtümer rechtmäßige Eigentümer von Land sein können, werden sie von einer Gemeinde verwaltet : Ihre Priester sind Beamte der Gemeinde ; die Gemeinde ist für die Verpachtung des heiligen Landes zuständig; sie sorgt für die ordnungs-

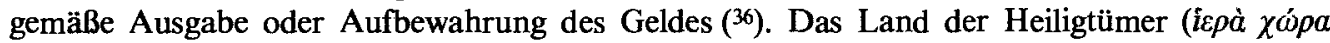
oder $\gamma \tilde{\eta})$ wird schließlich als Teil des Hoheitgebietes, der $\chi \hat{\omega} \rho a$, dieses einen Staates betrachtet $\left({ }^{37}\right)$. Manche Heiligtümer besaßen ausgedehntes Land an der Grenze zwischen zwei Staaten; die Kontrolle dieser Heiligtümer bedeutet dann für die zwei angrenzenden Staaten auch Kontrolle der Grenze und Besitz des Landes. Charakteristische Beispiele für solche Probleme bieten das Heiligtum der Artemis Limnatis an der Grenze zwischen Messenien und Lakonien ( ${ }^{38}$ ), das heilige Land der Artemis Leukophryene an einem Grenzgebiet zwischen Magnesia am Mäander und Priene (s.o. Anm. 37) und das Amphiaraos-Heiligtum bei Oropos $\left({ }^{39}\right)$, um dessen Besitz Athen und der boiotische Bund lange stritten.

(36) Allgemein HeGY, Temene, S. 77-87; 1. HAHN, «Eigentumsverhältnisse im archaischen Hellasm, in : J. HARMATTA (Hrsg.), Proceedings of the 7th Congress of the International Federation of the Societies of Classical Studies, Budapest, 1984, S. 79 und 82. Einige Beispiele für die Verpachtung heiligen Landes durch die Polis : Schwrzer, 62-63 =IG,

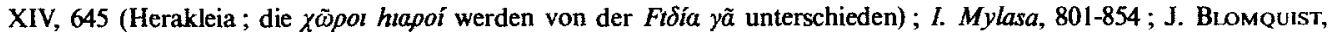
"The Dialect of Epizephyrian Locri», OpAth, 1 1, 1975, S. 20 (Lokroi) ; R. OsBORNE, «Social and Economic Implications of the Leasing of Property in Classical and Hellenistic Greece», Chiron, 18, 1988, S. 279-323 (passim). Vgl. auf Kreta die finanzielle Verwaltung des Heiligtums der Diktynna durch Polyrrhenia : I. Cret., II, xi, 3.

(37) Allgemein J. W. Jones, The Law and Legal Theory of the Greeks : An Introduction, Oxford, 1956, S. 198-199; A. R. W. HARrison, The Law of Athens. I. The Family and Property, Oxford, 1968, S. 235 ; K. W. WelWEl, "Abhängige Landbevölkerung auf "Tempelterritorien" im hellenistischen Kleinasien und Syrien", AncSoc, 10, 1979, S. 99 und 102.

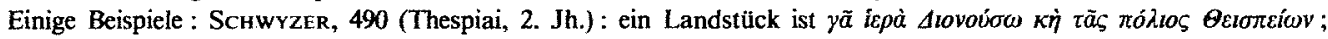
Lindos, 239, Z. $9-10$ (2. Jh.): s. die Formulierung im sehr fragmentarischen Text Év toĩ

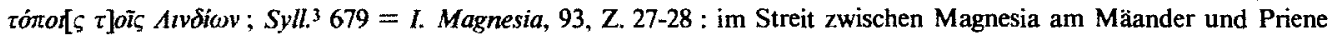
über die icpò $\chi \hat{c} \rho \dot{p}$ der Artemis Leukophryene (um 143) beanspruchten die Vertreter von Magnesia das Land für

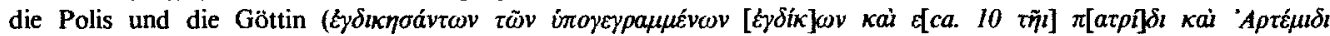

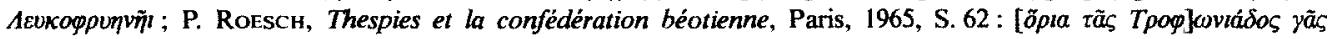

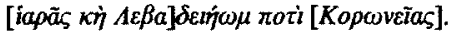

(38) Daverio Rocchi, Frontiera, S. 197-199.

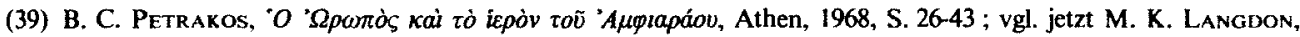
"An Attic Decree Concerning Oropos", Hesperia, 56, 1987, S. 47-58. 
Auch Beispiele für die zweite Kategorie - der Heiligtümer mit einer eigenen $\chi \omega ́ p a-$ fehlen nicht. Wenn wir von den großen kleinasiatischen Heiligtümern absehen, die in der hellenistischen Zeit fast wie Tempelstaaten hervortreten $\left({ }^{40}\right)$, - denn dieses Phänomen wurzelt in einer orientalischen Tradition -, gibt es Heiligtümer von Bünden und Amphiktionien, deren heiliges

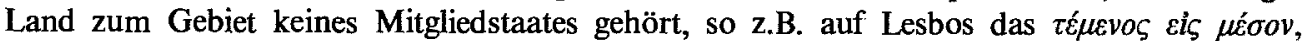
ein gemeinsamer Kultort von Mytilene, Methymna, Antissa und Erhesos ( $\left.{ }^{41}\right)$, oder die i $\varepsilon \rho \grave{a}$ $\chi$ $\omega ́ \rho a$ des Apollon Pythios, die - abgesehen von bestimmten Zeitabschnitten - vom delphischen Stadtgebiet streng zu trennen ist $\left({ }^{42}\right)$. Unklar ist dagegen, ob sich die Domäne des Apollon Ptoos in diese Kategorie einordnen läßt oder vielmehr als Teil des Gebietes der Stadt Akraiphia aufgefaßt wurde $\left({ }^{43}\right)$ : Aus einem amphiktionischen Dekret über die Asylie des

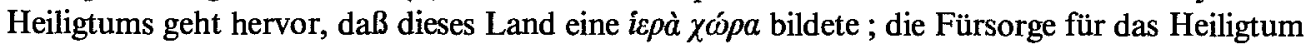
hatten jedoch gemeinsam der Prophetes, der Priester, der Böotische Bund und die Stadt Akraiphia. Der Status dieses Heiligtums ist vielleicht mit jenem des Heiligtums des Apollon von Aktion nach $216 \mathrm{zu}$ vergleichen : die Stadt Anaktorion, auf derem Land das Heiligtum lag, übergab es dem Akarnanenbund unter der Bedingung, daß sie Besitzer der älteren Weihgeschenke blieb und die Hälfte der Einnahmen am Fest einkassierte ( $\left.{ }^{44}\right)$. Aus der Tatsache jedoch, daß der Stadt Anaktorion die Hafengebühren und alle Einnahmen außerhalb der Zeit des Festes zustanden (Z. 43-45), kann man erschließen, daß das Heiligtum weiterhin als Teil des Gebietes von Anaktorion galt.

Es ist schwieriger außerhalb Kretas, Parallelen für den Status des Heiligtums des Hermes Kornisaios zu finden, eines Heiligtum auf Niemandsland, wo nur eine Stadt aufgrund vertraglicher Bestimmungen das Opferrecht ausübt. Von den Heiligtümern an der Grenze zwischen

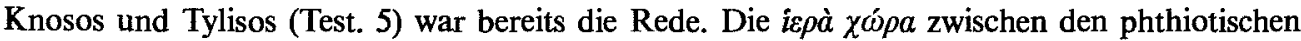
Theben und Halos stellt keinen vergleichbaren Fall dar: Die beiden Städte stritten um einen Landstrich ; statt ihn zu teilen, erklärten sie ihn für heilig und nutzten ihn gemeinsam (Mitte des 2. Jh.); das Opfer an die unbekannte Gottheit, der das Land geweiht wurde, wurde vom Ertrag des Landes finanziert und zwar so, daß entweder beide Städte gemeinsam oder jede getrennt Opfer darbrachten $\left({ }^{45}\right)$. Die Unterschiede sind evident : Dieses heilige Land war Kolv̀े $\chi \omega ́ \rho a$, nicht $\bar{\varepsilon} \rho \eta \mu \varsigma \chi \chi \omega ́ \rho a\left({ }^{46}\right)$; für das Opfer waren beide Nachbarstädte verantwortlich. Dem

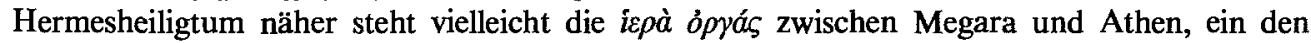

(40) Welwel, a.O., S. 97-118; H. Kreissig, «Zum Problem der Landvergabe im hellenistischen Orient", in : J.

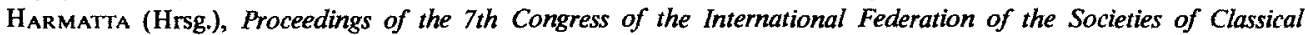
Studies, Budapest, 1984, S. 317-318; B. VIRGILIO, $l /$ "Tempio stato" di Pessinunte fra Pergamo e Roma nel iti secolo a.C., Pisa, 1981, bes. S. 49-83 ; P. DeBord, Aspects sociaux et économiques de la vie religieuse dans l'Anatolie grécoromaine, Leiden, 1982, S. 127-180.

(41) Daverio Rocchi, Frontiera, S. 38 mit Anm. 55.

(42) KahrStedt, Heiliges Land, S. 749-757, besonders 750-754. Vgl. jetzt G. Daverıo Rocchi, "La hierà chora di Apollo, la pianta di Cirra e i confini di Delphin, in: M. M. Mactoux-E. Geny (Hrsg.), Mélanges $P$. Lévêque

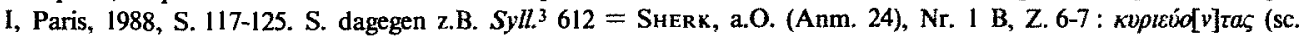

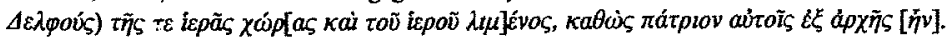

(43) $S y l l .{ }^{3} 635=\operatorname{LSS} 73$ (ca. 228/6).

(44) Chr. НАвіснт, «Eine Urkunde des akarnanischen Bundes», Hermes, 85, 1957, S. 98-102; Staatsverträge, 111, 523.

(45) F. Delphes, III, 4, 355 ; J. Pouilloux (ebenda) denkt an das Heiligtum der Athena Itonia ; s. aber J. Bousqurt, "Inscriptions de Delphes", BCH, 101, 1977, S. 458. Zum Opfer s. Bousquet, a.O., S. 457-458; G. DAux, "Notes de lecture", $B C H, 102,1978$, S. 617-618. Zu dieser Inschrift s. jetzt Daverio Rocch1, Frontiera, S. 152-155.

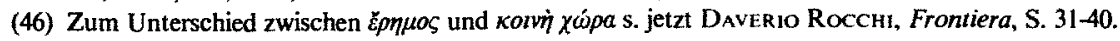


eleusinischen Göttern geweihtes Land, das bis zur Mitte des 4. Jh. allem Anschein nach Niemandsland war $\left({ }^{47}\right)$.

\section{Zur besonderen rechtlichen Stellung vordorischer Heiligtómer Kretas}

Aus dem hier vorgestellten Material ergeben sich also zunächst keine gravierenden Unterschiede zwischen Kreta und dem Rest des griechischen Mutterlandes. Freilich ist das parallele Vorhandensein von Heiligtümern verschiedener Kategorien in einem beschränkten Raum und zur selben Zeit im Falle der ostkretischen Städte einmalig und lehrreich. Unser Material spiegelt allerdings die momentane Situation um das Jahr $114 \mathrm{v}$. Chr. wider; und dieser augenblickliche Zustand verzerrt möglicherweise das Bild ; vielleicht war die Vorgeschichte dieser Heiligtümer viel bewegter, als sie uns die drei Staatsverträge der späthellenistischen Zeit auf den ersten Blick erkennen lassen.

Wie wir schon gesehen haben, gibt es Hinweise darauf, daß auch das Heiligtum des Ares und der Aphrodite früher eine eigene $\chi \omega \dot{p} p a$, also vielleicht eine Sonderstellung, besaß. Und was das Heiligtum des Hermes Kornisaios betrifft, kann man nicht ausschließen, daß es in älterer Zeit nicht auf Niemandsland, sondern auf einer eigenen $\chi \omega \dot{\omega} \rho \alpha$ lag. Hatten vielleicht einstmals alle drei Heiligtümer dieselbe rechtliche Stellung gehabt, als Heiligtümer auf eigenem Land, das zum Hoheitsgebiet keiner Polis gehörte? Hatten sie vielleicht ursprünglich eine Sonderstellung, möglicherweise als Zentrum lokaler "Amphiktionien" bzw. als "pankretische" Heiligtümer, die sie dann im Laufe der hellenistischen Zeit verloren haben, als die von Landnot bedrängten kretischen Städte $\left.{ }^{48}\right)$ die icpà $\chi \omega ́ p \alpha$ überragender Heiligtümer beanspruchen mußten?

Mit dieser Frage ist eine zweite eng verknüpft, nämlich, ob die vordorische (minoische und achäische) Vergangenheit Kretas, die gerade in Ostkreta bis in die hellenistische Zeit hinein sehr lebendig war (man denke etwa an die eteokretischen Inschriften von Praisos und Dreros, Inschriften in einer vorgriechischen Sprache noch im 3. Jh.) ( $\left.{ }^{49}\right)$, die Stellung von Heiligtümern beeinflußt hat. Man sollte nicht vergessen, daß das Heiligtum des Zeus Diktaios, für welches ich eine Sonderstellung vermutet habe, wahrscheinlich einen minoischen Vorgänger hatte ${ }^{50}$ ), und ähnliches ist auch im Fall des ảoxaĩov 'Agpodíoıov in Sta Lenika (s. Anm. 11) und des Kultortes des Hermes Kornisaios ( ${ }^{51}$ ) denkbar.

Die Beantwortung dieser Fragen ist angesichts der Mängel unseres Materials nicht möglich. Hier kann ich nur einige Hinweise darauf zusammenstellen, daß manche alte, von städtischen Zentren entfernte Kultorte Kretas nicht auf dem Territorium einer Stadt lagen, daß vielmehr

(47) Daverio Rocchi, Frontiera, S. 38, 186-194.

(48) Zur Landnot im hellenistischen Kreta s. Perropoulou, a.O. (Anm. 2), S. 47-48 und 110-112.

(49) $\mathrm{Zu}$ den eteokretischen Inschriften s. Y. Duhoux, Létéocrétois : Les textes - La langue, Amsterdam, 1982.

(S0) Bosanquet, a.O. (Anm. 4), S. 66-68.

(51) Die Lesung des Epitheton ist leider nicht sicher; es geht vielleicht auf einen vorgriechischen Ortsnamen zurück. Die kretischen Hermes-Kulte gehen oft mindestens z.T. auf minoische Kulte zurück : s. R. F. WiLlerrs, Cretan Cults

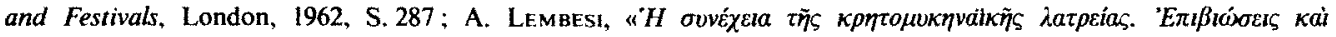

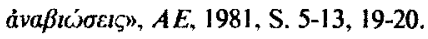


mehrere Städte an Bauarbeiten, Weihungen und Opfern beteiligt waren; letzteres schließt natürlich nicht aus, daß diese Städte miteinander um den Besitz oder die Kontrolle des Kultortes konkurrierten ; im Laufe der klassischen und vor allem der hellenistischen Zeit mag es der einen oder anderen unter ihnen gelungen sein, das Heiligtum in ihren Besitz zu bringen. Ich nenne kurz drei Beispiele mit der einschlägigen, leider immer sehr mangelhaften Dokumentation :

\section{Das Gipfelheiligtum auf dem Berg Juktas (Iyktos) in der Nähe von Archanes.}

Der Kult in der minoischen Zeit in einem Temenos um einer Erdspalte ist durch neue Ausgrabungen ( ${ }^{52}$ ) eindeutig belegt, auch wenn der Charakter des Kultes (vermutlich Kult einer Gottheit der Fruchtbarkeit) im Dunklen bleibt. Aus Inschriften wissen wir, daß in historischer Zeit Poseidon und Zeus dort verehrt wurden (53), während die literarische Öberlieferung das Grab des Zeus an diesem Ort lokalisierte (54). Wem gehörte nun dieser Kultort ? Aus dem Staatsvertrag zwischen Knosos und Tylisos (s.o., Test. 5) geht wohl hervor, daß dieser Kultort weder auf dem Territorium von Knosos noch auf dem Territorium von Tylisos lag, denn die Frage des Opferrechtes wurde im Vertrag geregelt. Wir haben es also entweder mit Niemandsland an der Grenze zweier Staaten (vgl. o.) oder mit einem Heiligtum auf eigenem Land zu tun.

\section{Das Heiligtum des Hermes Dendrites in Simi bei Biannos.}

Ein Kult wurde hier ununterbrochen von der mittelminoischen bis in die Kaiserzeit hinein praktiziert (55). Auch hier ist die Zugehörigkeit des Heiligtums zu einer Stadt unsicher. Es gibt dagegen ein starkes Indiz, daß das von einem Peribolos ummauerte Heiligtum keiner einzelnen Polis gehörte, daß gleichzeitig mehrere Städte am Kult teilnahmen. Die meisten hellenistischen Inschriften aus diesem Ort sind Dachziegel des korintischen Typus. Viele tragen Personennamen, von Dedikanten, Herstellern oder Beamten; darunter findet man Männer aus Lyttos, Priansos, Hierapytna und dem Stamm der kretischen Arkader (56). Auf einem

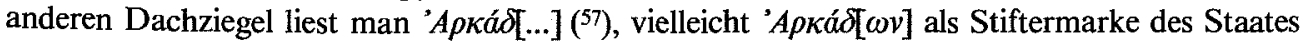
der Arkader; die Inschrift $K v \omega \sigma r[\ldots]$ auf einem dort geweihten Gefäß weist schließlich auf Weihung entweder der Stadt Knosos bzw. eines Knosiers oder eines Mannes mit dem Namen Knosion hin ( ${ }^{58}$ ). Sicher ist also, daß die für die hellenistischen Bauarbeiten verantwortlichen Kultteilnehmer aus mehreren Städten kamen ( ${ }^{59}$ ). Da wir auf Kreta keine Parallele dafür haben, daß Privatleute Bauarbeiten in einen Heiligtum übernahmen (wie etwa die Alkmeoniden in Delphi), ist eher zu vermuten, daß dieser Kultort mehreren Städten gemeinsam war. Diese

(52) Zur Geschichte des Kultortes s.o. Anm. 4.

(53) Poseidon: I. Cret., I, viii, 4* = Staatsverträge, II, 148 A 14-16; Zeus : I. Cret., I, viii, 17.

(54) VerbrugGen, a.O. (Anm. 29), S. 63-67.

(55) $\mathrm{Zu}$ den dortigen Grabungen s.o. Anm. 4. Die Ergebnisse der neuesten Kampagnen in Ergon, 1985 (1986), S. $72-76$; 1986 (1987), S. 138-139; 1987 (1988), S. 129-133; 1988 (1989), S. 149-156; 1989 (1990), S. 140-141.

(56) Der Lyttier Damithales: s. A. Lembesi, PAAH, 1972, S. 202; der Arkader Satyros : ebenda ; der Arkader

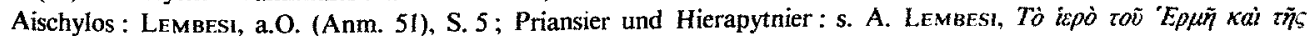

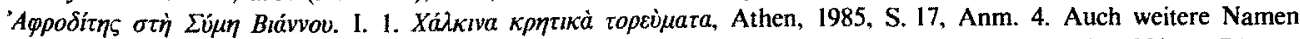
sind in Lyttos bz.w. Arkades belegt: s. A. Chaniotis, "Some More Cretan Names", ZPE, 77, 1989, S. 75, s.v. "Matrodoros (Lyttos)", S. 77, s.v. "Pamphias (Arkades)"; Nikanor, Sohn des Theomnastos: SEG, XXVI, 1046; beide Namen sind mehrmals in Lyttos belegt : s. P. M. Fraser-E. Matthews, A Lexicon of Greek Personal Names,

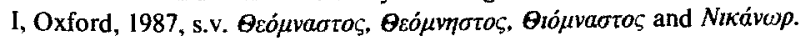

(57) A. LembesI, PAAH, 1973, S. 197.

(58) Chaniotis, a.O. (Anm. 56), S. 75, s.v. Knosion.

(59) Vgl. LemBesi, a.O. (Anm. 51), S. 4. 
Vermutung wird möglicherweise durch den Namen dieses Gebietes erhärtet. Es heißt ispòv òpos, "heiliger Berg" $\left(^{(0)}\right.$; es ist also ein einer Gottheit geweihtes Land.

\section{Die Kultgrotte des Zeus Idaios, auf dem Berg Ida.}

Auch hier fängt der Kult spätestens in der mittelminoischen Zeit an und geht fast ununterbrochen in der geometrischen, archaischen, klassischen, hellenistischen und römischen Zeit weiter ${ }^{(6)}$; auch hier gibt es widersprüchliche Hinweise sowohl auf Kontrolle durch eine einzige Stadt als auch auf eine gemeinsame Verantwortung mehrerer Städte (62). In einem Vertrag zwischen Gortyn und der abhängigen Gemeinde der Rhizenier aus dem späten 5. Jh. v. Chr. heißt es $\left({ }^{63}\right)$ :

«Zu den folgenden Bedingungen kamen die Rhizenier, unter Beibehaltung ihrer eigenen Gesetze und Gerichte zu einem Abkommen mit den Gortyniern, mit der Verpflichtung, alle zwei Jahre Opfertiere im Werte von 350 Stateren zum (Zeus) Ida zu schicken» (Übers. von H. Bengtson).

Dieses Opfer ähnelt einer Tributzahlung, die jedoch nicht den Gortyniern, sondern dem Zeus vom Ida zugute kommt. Dies erweckt den Eindruck, daß zu diesem Zeitpunkt Gortyn diesen Kultort kontrollierte; denn in einem analogen, aber viel späteren Vertrag der Gortynier mit der abhängigen Gemeinde der Bewohner von Kaudos (frühes 2. Jh.), gehört zu den Verpflichtungen der Kaudier, die ebenso wie die Rhizenier Freiheit und Autonomie erhielten, einen Zehnten des auf ihre Insel gestrandeten Gutes an das gortynische Heiligtum des Apollon Pythios zu liefern ( ${ }^{64}$ ). Wenn in diesem Fall die "Tributzahlung" einem Heiligtum von Gortyn gilt, muß man dasselbe auch für die ältere "Tributzahlung" annehmen. Wie lange das Heiligtum unter der Kontrolle der Gortynier blieb, wissen wir nicht. Auch aus einer Inschrift des 4. Jh. geht hervor, daß Gortyn dem Zeus auf dem Ida alle drei Jahre (?) opferte ( ${ }^{65}$ ).

Gortyn war jedoch nicht die einzige Stadt, die mit dem Heiligtum des Zeus Idaios verbunden war. Aus einem fragmentarischen Volkbeschluß von Axos (2./1. Jh.) erfahren wir (66), daß in dieser Stadt gewisse Strafgelder diesem Heiligtum zugute kamen. Auch Axos hatte also enge Verbindungen zum Kultort auf dem Ida ${ }^{\left({ }^{67}\right)}$. Für den quasi pankretischen Charakter dieses Kultortes spricht ferner der Bericht des Polybios, daß Kydonia und Apollonia ihren Isopolitievertrag hier aufstellten $\left({ }^{68}\right)$, sowie die Erwähnung des Zeus Idatas als Schwurgottheit in Verträgen von Gortyn, Hierapytna, Priansos, Lyttos, Olus und Eleutherna $\left({ }^{69}\right)$ - wobei aller-

(60) Ptolemaeus, Geogr., 3, 17, 4 ; Lembesi, a.O. (Anm. 56), S. 18.

(61) Zu den Ergebnissen der neuen Ausgrabungen s. die in Anm. 4 angeführte Literatur.

(62) Vgl. allgemein Faure, Cavernes, S. 126, der eine Kontrolle durch Gortyn vermutet; in der hellenistischen Zeit sei das Heiligtum ein "sanctuaire fédéral" geworden.

(63) I. Cret., IV, 80 = Staatsverträge, II, 216, Z. 1-3 ; vgl. jetzt Petropoulou, a.O. (Anm. 2), S. 85.

(64) I. Cret., IV, 184 A 18-19.

(65) I. Cret., IV, 146.

(66) I. Cret., II, v, 35.

(67) G. CAPDevill.e, "L'oracle de l'Ida crétois», Kernos, 3, 1990, S. 92-94 vermutet, daß die Kulthöhle auf dem Territorium von Axos lag; die mythologische Uberlieferung, die die idäischen Daktyloi und ihre Mutter Anchiale sowohl mit der Idäischen Grotte als auch mit Axos verbindet (s. vor allem APollonios RHoD., Arg., 1, 1131 : yaíns

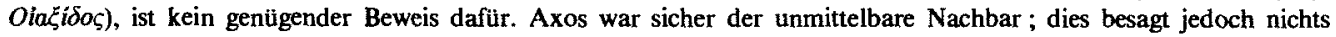
über die Zugehörigkeit des Heiligtums.

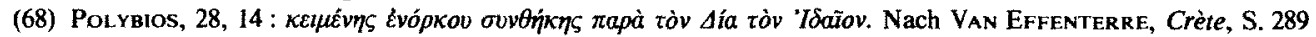
bedeutet diese Stelle, daß Zeus Idaios nur Schwurgott im Vertragseid war. $\Pi$ $\propto \rho \dot{\alpha}+$ Name einer Gottheit bezeichnet jedoch ein Heiligtum : s. P. CharNeux, "Du côté de chez Héra», BCH, 111, 1987, S. 207-223.

(69) l. Cret., I, xviii, 9, C 5 (Bündnis- und Isopolitievertrag zwischen Lyttos und Olus, 111/110); I. Cret., IV, 174, 7. 57 (Bündnisvertrag zwischen Gortyn, Hierapytna und Priansos, fruihes 2. Jh.) ; SEG, XXIII, $547=$ Staats- 
dings auch hier die oben (im Falle des Zeus Diktaios, s. Anm. 33) angesprochenen Probleme gelten. Die Ausstrahlung der Idäischen Grotte auf ganz Kreta bestätigen schließlich die Münzfunde, unter denen sich nicht nur Münzen zahlreicher Städte Kretas finden (Chersonesos, Eleutherna, Gortyn, Itanos, Knosos, Kydonia, Lyttos und Tylisos), sondern auch die wohl offizielle Weihung eines Goldstaters Alexanders des Großen von Polyrhenia im späten 2. Jh. $\left({ }^{70}\right)$. Es ist also sicher, daß dieser traditionsreiche Kultort nicht nur Kultteilnehmer aus verschiedenen Orten anzog, sondern vielmehr viele kretische $S t$ äd te am dortigen Kult offiziell teilnahmen. Dies war an sich möglich, auch wenn der Kultort nur einer einzigen Stadt gehört hätte (71). Man darf aber die Möglichkeit einer Art Amphiktionie nicht ausschließen. Im übrigen hatte

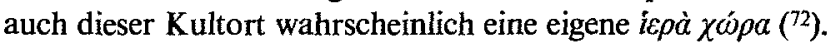

Es ist sicher noch zu früh, darüber zu spekulieren, ob manche minoische Kultorte, die weit von städtischen Zentren entfernt waren, auf Bergen oder in der Eschatia kretischer Poleis, in der dorischen Zeit eine besondere rechtliche Stellung besaßen. Man darf jedoch diese Indizien nicht außer acht lassen. Im Laufe der klassischen und vor allem der hellenistischen Zeit gingen auf jeden Fall viele dieser Heiligtümer ihrer Sonderstellung verlustig und gelangen unter die Kontrolle einer einzigen Polis. Das ist das Bild, daß uns die späthellenistischen Staatsverträge vermitteln.

\section{Ausblick}

Wenn ich nun abschließend die Frage unseres Rahmenthemas stelle, Religion und Politik, Integration oder Unabhängigkeit, und sie im Hinblick auf dieses kretische Material umformuliere, Heiligtum und Polis, Integration oder Unabhängigkeit, so kann ich meine Ratlosigkeit nicht verhehlen. Die Faktoren, die die vielfältigen, wechselseitigen und stets wechselnden Beziehungen zwischen Religion und Politik im von mir vorgestellten Material beeinflußten, waren sehr oft profaner, politischer Natur : der Wunsch nach landwirtschaftlich nutzbarem Land zwang die Hierapytnier dazu, in dem von ihnen dem Zeus geweihten Land ein Dorf zu gründen; und es war nicht eine tiefe Religiosität, was sie dazu geführt hatte, das Land dem Zeus zu weihen, sondern vielleicht nur die Absicht, die Rechtsansprüche der Itanier zu schwächen. Auf der anderen Seite aber fiel in Kreta eine Jahrtausende alte kultische Tradition schwer ins Gewicht.

verträge, III, 552, Z. 51 (Bündnisvertrag zwischen Olus und Rhodos, ca. 200 v. Chr.). Dieses Epitheton wird von H. VAN EFFENTERRE in einem neuen Vertrag zwischen Eleutherna und einer anonymen Stadt ergänzt ; die Inschrift wird in A. KaLPaxis (Hrsg.), Elcielepva, 1, veröffentlicht; den Hinweis verdanke ich Prof. Ath. Kalpaxis; jetzt:

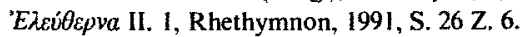

(70) J. SAK KEllaRAK IS, "L'Antro Ideo ..." (Anm. 4), S. 38-40, Abb. 22 ; Der Stater wird zusammen mit den restlichen

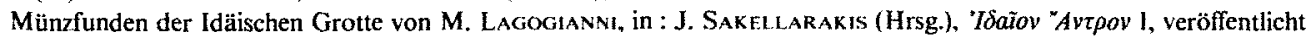
werden.

(71) Viele kretische Staatsverträge genehmigen nämlich den Bürgern des einen Vertragspartners die Teilnahme an den Festen des anderen : z.B. I. Cret., I, viii, 13, Z. 7-9 (Hierapytna-Knosos, 2. Jh.); I. Cret., I, xvi, 5, Z. 42-45 (Lato-Olus, spätes 2. Jh.) ; I. Cret., I, xviii, 9 B 10-14 (Lyttos-Olus, spätes 2. Jh.) ; I. Cret., HI, iii, 3 B 1-2 (HierapytnaLyttos, 3./ 2. Jh.) ; I. Cret., III, iii, 4, Z. $38-40$ (Hierapytna-Priansos, frühes 2. Jh.) ; I. Cret. III, iv, I B = Staatsverträge, III, 554, Z. 68-78 (Hierapytna-Praisos, frïhes 3. Jh.) ; I. Cret., IV, 174, Z. $37-39$ (Gortyn-Hierapytna-Priansos, frühes 2. Jh.) ; SEG, XXVI, 1049. Z. 48-49 (Hierapytna-Lato, spätes 2. Jh.).

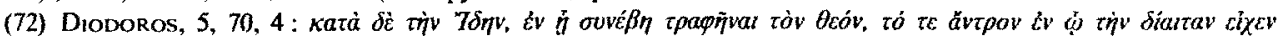

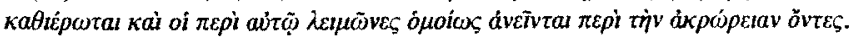


Das religiöse Erbe der Minoer, welches nicht nur in manchen Kulten, sondern vielleicht auch in der Stellung mancher Kultorte erkennbar wird, hat möglicherweise manchen kultischen Zentren in schwer zugänglichen, aber immer noch von der Aura einer uralten Heiligkeit umgebenen Orten, bis weit in die dorische Zeit hinein eine gewiße Selbständigkeit sowie einen pankretischen Charakter erhalten.

Angelos Chaniotis (Heidelberg) 


\section{Testimonien}

I. Der Streit zwischen Lato und Olus um das Heiligtum des Ares und der Aphrodite (118-110 v. Chr.).

T 1. I. Cret., I, xvi, 3 (118 v. Chr.), Abkommen zwischen Lato und Olus über die Vermittlung der Knosier. Kaì ảv-

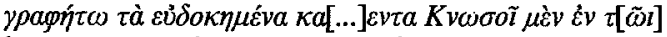

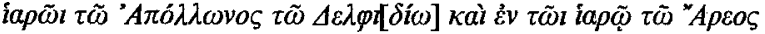

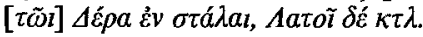

T 2. VAN EFfenterre, Querelles, S. 35-36 (ca. 115, Urteil der Knosier).

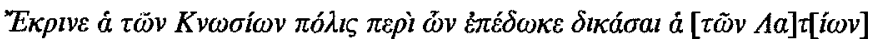

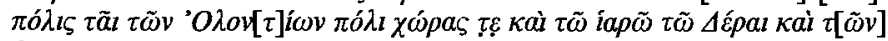

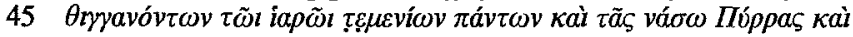

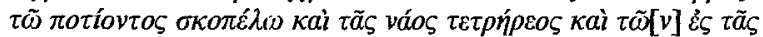

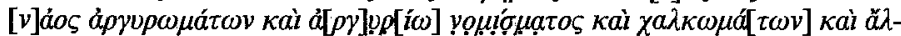

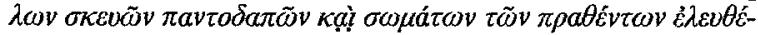

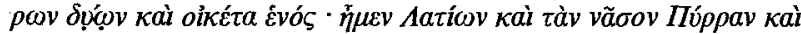

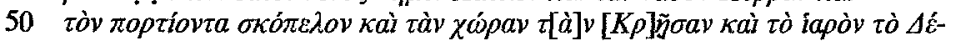

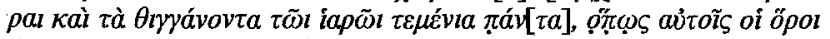

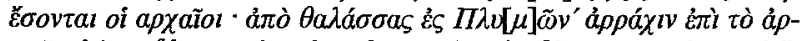

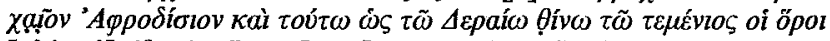

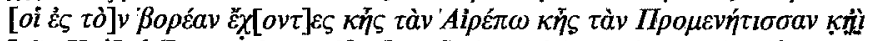

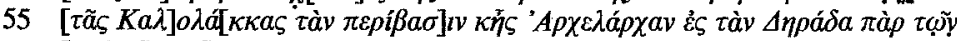

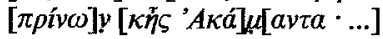

T 3. VAN Effenterre, Querelles, S. 36 (ca. 113 y. Chr., Urteil der Römer).

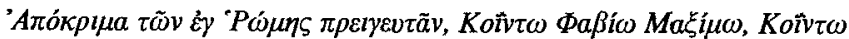

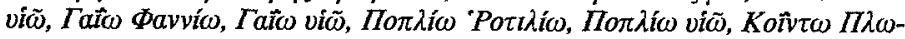

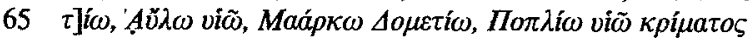

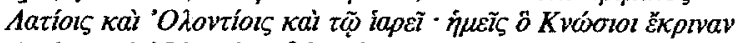

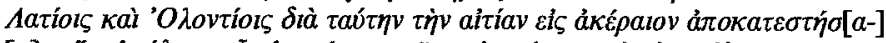

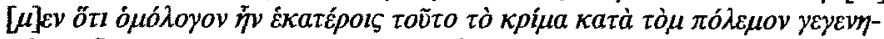

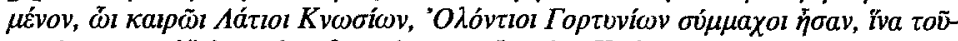

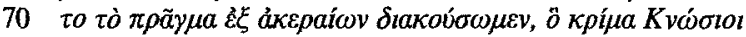

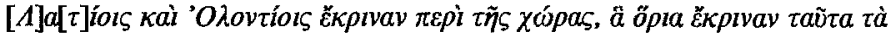

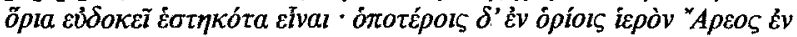

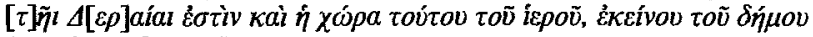

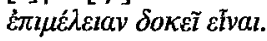

II. Das Heiligtum des Hermes Kornisaios zwischen Lato und Hierapytna (111/110 v. Chr.).

T 4. SEG, XXVI, 1049 (Vertrag zwischen Lato und Hierapytna).

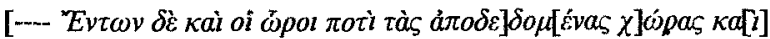

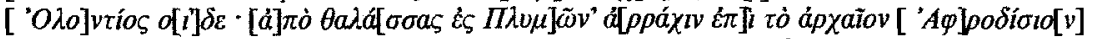

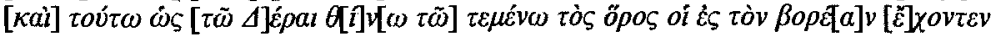

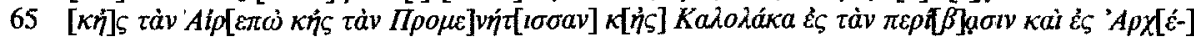

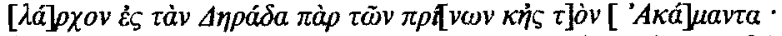

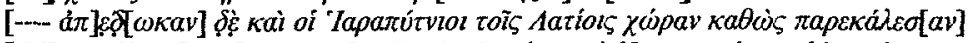

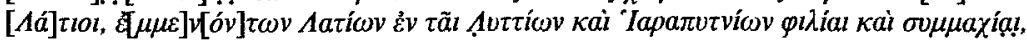




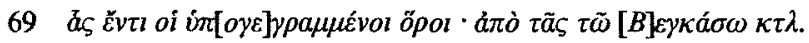

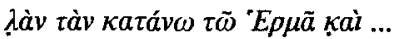
... $\mu \varepsilon \delta \tau a \dot{\varepsilon} \zeta \tau \grave{̣}[v \kappa \varepsilon \varphi a-]$

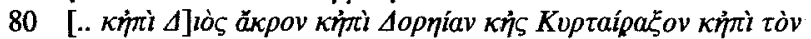
$K a \tau \alpha \beta[\alpha] \theta[\mu] \dot{\partial v} \kappa a \grave{l} \pi \varepsilon \rho l a \mu-$

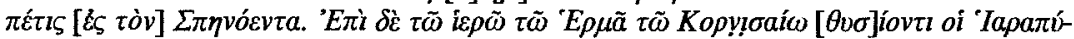

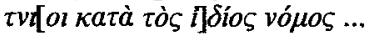

$67[--\alpha \pi] k \not \omega K a v]$ Chaniotis. $81[\theta v \sigma] i ́ o v \tau l$ Chaniotis.

T 5. Staatsverträge II, 148 (Vertrag zwischen Knosos und Tylisos, Mitte des 5. Jh.).

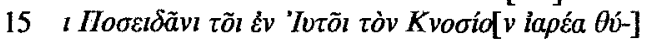

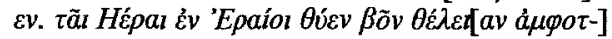

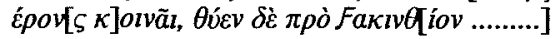

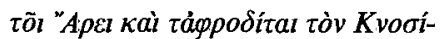

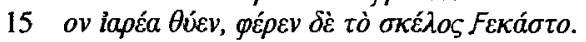

III. Das Heiligtum des Zeus Diktaios zwischen Hierapytna und Itanos (141-112 v. Chr.).

T 6. I. Cret., III, iv, 9 (Urteil der Richter aus Magnesia, 113/112 v. Chr.).

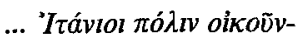

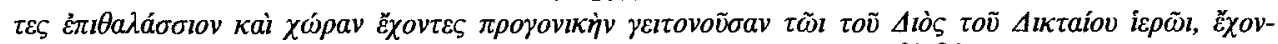

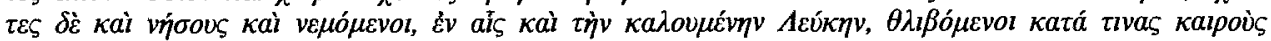

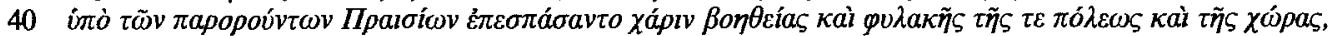

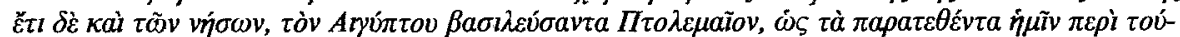

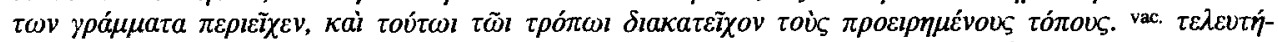

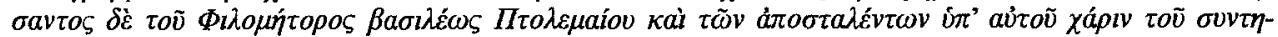

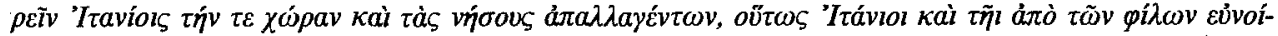

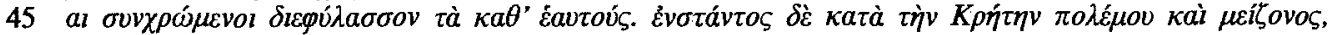

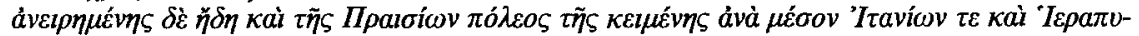

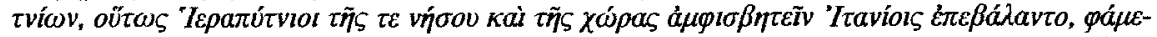

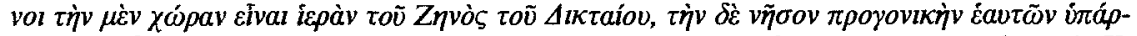

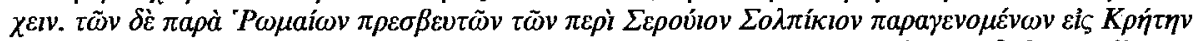

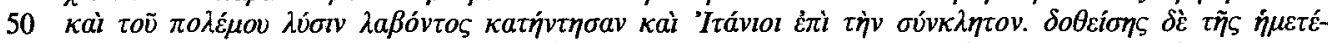

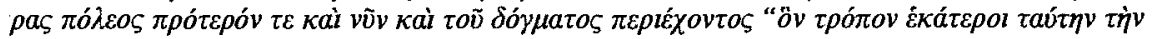

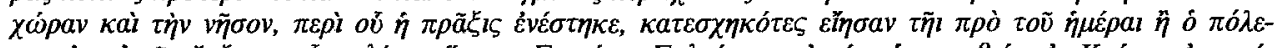

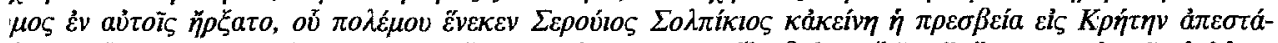

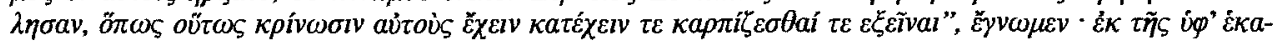

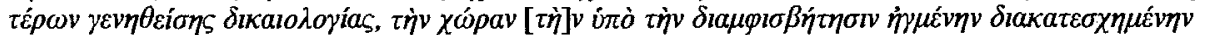

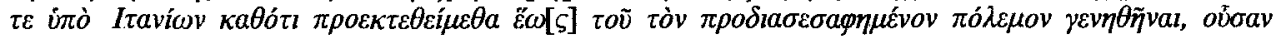

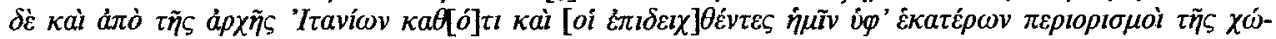

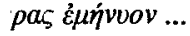

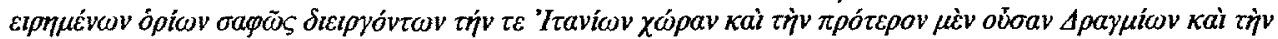

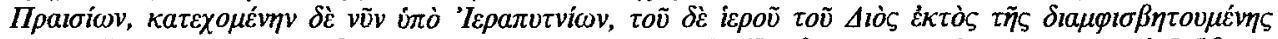

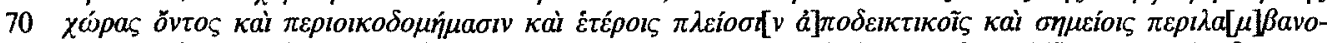

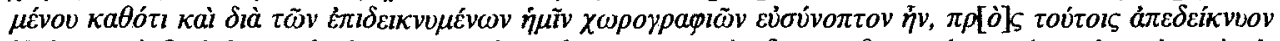

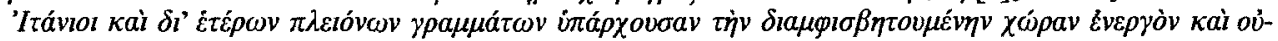




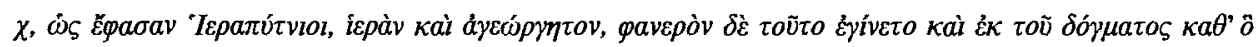
Ékpíva-

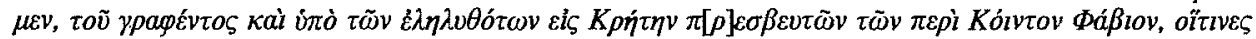

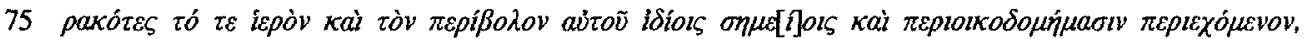
$\varepsilon \omega-$ $\dot{\varepsilon} \omega \rho \alpha-$

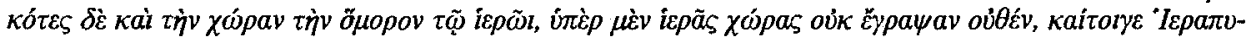

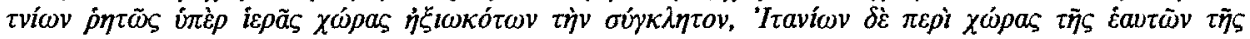

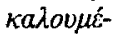

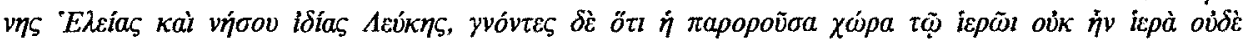
àjeciopros, i-

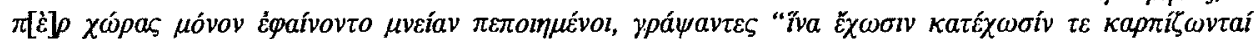
$\tau \varepsilon "$,

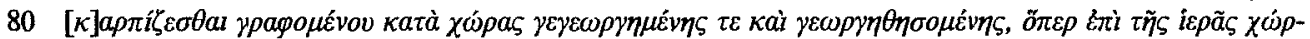

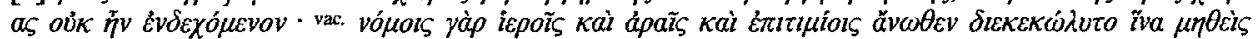
Ev $\tau \tilde{\omega} i$ -

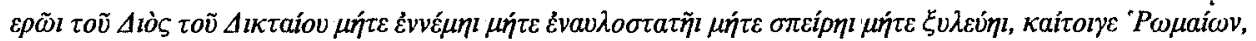

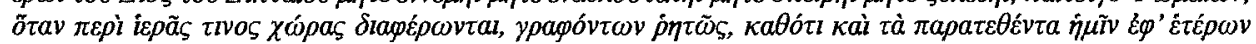

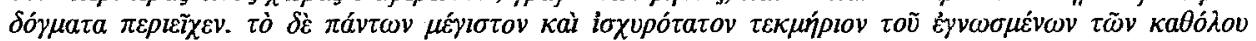
$\pi \rho a-$

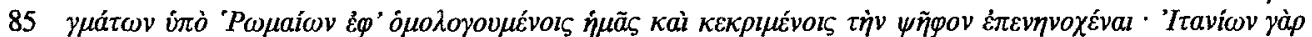

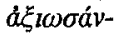

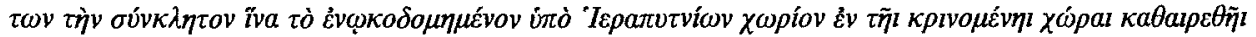

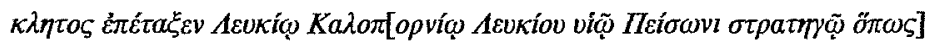
$\dot{\eta} \sigma \dot{v} v-$

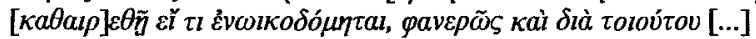

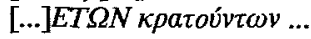

T 7. I. Cret., III, iv, 10 (Die Argumente der Hierapytnier).

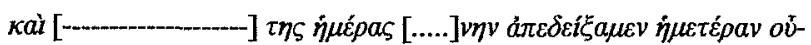

$15 \sigma a v[-\ldots$

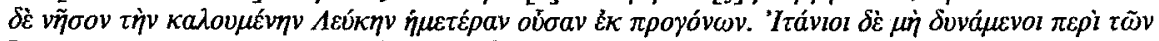

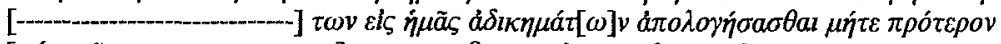

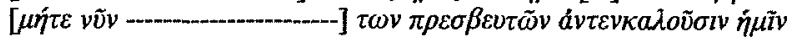

$20 \pi$ romoa

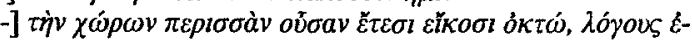

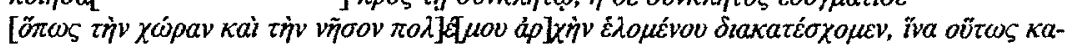
$\tau \hat{\varepsilon} \chi \chi \omega] u \varepsilon v \cdot \ldots$ 